\title{
Understanding Cultural Omnivores: Social and Political Attitudes
}

\author{
May 14, 2018
}

\begin{abstract}
In this paper, I use data from the British Household Panel Survey and Understanding Society to investigate the social and political attitudes of cultural omnivores. I report a threefold typology of cultural consumption in the domains of music and visual arts that is consistent with previous research. Then by linking data across the two panel surveys, I show that cultural omnivores have quite a distinctive profile of social attitudes. Specifically, omnivores are more trusting and risk-taking. They hold more favourable views about the European Union, and they tend to eschew subnational identities. Omnivores are politically more engaged. But they are not more 'class conscious', nor are they particularly left-wing or right-wing on distributional issues. When asked what is important to the sense of who they are, the two most important status-conferring attributes, i.e. profession and education, are not more salient to omnivores than to others. But omnivores are more extravert and open to new experiences. Taken together, these results suggest that omnivorousness is an expression of cosmopolitan postmaterialism rather than a new form of distinction.
\end{abstract}




\section{Introduction}

Recent research on the social stratification of cultural consumption has converged to several key findings. First, although individuals in advantaged social positions are more likely than others to consume highbrow culture, they do not have any general aversion against other cultural forms. Indeed, consumers of highbrow culture are just as likely to consume middlebrow or popular culture, leading Peterson and Simkus (1992) to describe them as cultural omnivores (see also Peterson and Kern, 1996; Van Eijck, 2001; López-Sintas and García-Álvarez, 2002; Bunting et al., 2008; Bennett et al., 2009; Chan, 2010).

Second, often a majority, or at least a large minority, of individuals in advantaged positions do not consume highbrow culture at all. Peterson (1992, p. 248) reports that 'just $30 \%$ of those in the highest status group say they like classical music best and only another $6 \%$ say they like opera best. Thus, $64 \%$ of the top group do not fit the model of the aesthetically exclusive snob.' It follows from the first two points that often only a minority of even the most advantaged social groups are omnivores (see e.g. Chan and Goldthorpe, 2007b, pp. 7-8).

Third, cultural consumption is differentiated by age, gender, parental status, and other demographic variables. It is also stratified by education, income, and social status. ${ }^{1}$ Taken together, these findings lend more support to the omnivore-univore argument (Peterson and Simkus, 1992) than the

\footnotetext{
${ }^{1}$ There is a bivariate association between social class and cultural consumption. But this association is explained away when social status and education are included in the model (see Chan and Goldthorpe, 2005, 2007b,c).
} 
class-culture homology argument (Bourdieu, 1984) or the individualisation argument (Bauman, 1988; Giddens, 1991).

But who are the omnivores? A composite demographic profile can be gleaned from previous research. Omnivores tend to be well-educated, of higher social status, living in urban areas, without young children at home, and so on (see the chapters in Chan, 2010). Beyond these sociodemographic characteristics, however, we know relatively little about them. To fill in this gap, this paper explores the subjective dimension of cultural consumption. Do omnivores and univores hold different social and political values? And do they have different personality traits? These questions are of considerable interest in themselves. But they also speak to an important but unresolved issue about the very meaning of cultural omnivorousness.

Peterson and Kern (1996, p. 904) argue that although omnivorous taste 'signifies an openness to appreciate everything,' it does not mean that 'the omnivore likes everything indiscriminately.' Bryson (1996, p. 884) shows that individuals with tolerant musical taste have 'a specific pattern of exclusiveness ... Those genres whose fans have the least education .... are also those most likely to be rejected by the musically tolerant.'

This points to an ambiguity in the meaning of cultural omnivorousness. As Chan and Goldthorpe (2007b, p. 3) observe, 'on the one hand, omnivores may be seen as essentially tolerant individuals ... who have a general openness to other cultural styles ... perhaps, a desire to experiment with different kinds of cultural consumption ... On the other hand, omnivores may be seen as expressing a new aesthetics which, even if more inclusive and "cosmopolitan" than that of earlier cultural elites, is no less directed towards the 
demonstration of cultural and social superiority ...cultural consumption is still seen as playing a central part in creating symbolic boundaries and in status rivalry and competition.'

Chan and Goldthorpe (2007b) hedge their bets on the meaning of omnivorousness. Other scholars, however, are less equivocal. For example, Ollivier (2008, p. 123) asserts that omnivorousness is 'the new "aesthetics of elite status" which replaced highbrow snobbishness as a means of class distinction.' She maintains that it is 'a new form of cultural capital, in the Bourdieusian sense' (Ollivier, 2008, p. 142). Warde et al. (2008, p. 164) see 'more than a hint that in Britain an omnivorous orientation is itself a way of negotiating and demonstrating a form of distinction.' In a study of an elite boarding school in America, Khan (2011, p. 152) posits that omnivorous consumption 'is itself a symbolic marker ... this omnivorousness, become their own mark of distinction.' Similarly, Coulangeon (2017, pp. 160-161) argues that the '[c]ultural privilege of the elite [in France] seems to be increasingly defined by the combination of involvement in highbrow culture with openness to cultural diversity ... it also goes hand in hand with a kind of self-segregation of the elite which is not fully consistent with the concept of cosmopolitanism ... openness to cultural otherness is not incompatible with distance from the others.' ${ }^{2}$ Plus ça change, plus c'est la même chose.

If Ollivier (2008), Warde et al. (2008), Khan (2011) and Coulangeon (2017) are correct in their interpretation, then the existence of cultural omnivores poses less of a challenge to Bourdieu's argument. After all, omniv-

\footnotetext{
${ }^{2}$ See also Peterson (2005); Prior (2005); Bellavance (2008); Roose et al. (2012); Glevarec and Pinet (2017).
} 
orousness is a form of distinction. But are they correct? In Distinction, Bourdieu (1984, p. 7) argues that '[t]he denial of lower, coarse, vulgar, venal, servile ... enjoyment ... implies an affirmation of the superiority of those who can be satisfied with the sublimated, refined, disinterested, gratuitous, distinguished pleasures forever closed to the profane. That is why art and cultural consumption are predisposed, consciously and deliberately or not, to fulfill a social function of legitimating social differences' (emphasis added). Clearly, status rivalry and symbolic boundaries are central to Bourdieu's argument. Many Bourdieusian scholars also share this view. Jenkins (1992, p. 129), for example, observes that 'Bourdieu is not just interested in cultural taste(s), but also in the way in which those tastes arise out of, and are mobilised in, struggles for social recognition or status' (emphasis added). Lamont and Molnár (2002, p. 172) write that '[d]ominant groups generally succeed in legitimizing their own culture and ways as superior to those of lower classes ...' (emphasis added).

Thus, to regard cultural omnivorousness as a form of distinction is, to paraphrase Bourdieu, to see omnivores acting, 'consciously and deliberately or not', to legitimise social differences. This view is, in principle, empirically testable. But since supercilious attitudes, or at least their public expression, have become less acceptable, omnivores are unlikely to admit to feeling superior to others. Moreover, they might not be fully aware of the status motivations that drive their cultural consumption. For these reasons, we do not have survey evidence that would directly reveal what omnivorousness means. Nonetheless, it is possible to determine whether cultural omnivores have a distinctive profile of attitudes in other domains. Such information will 
give us a sense of the kind of individuals omnivores are. In other words, we could clarify the meaning of omnivorousness indirectly by considering how cultural consumption 'is embedded in larger systems of meaning' (DiMaggio, 1996, p. 161).

\subsection{Previous research on the social and political atti- tudes of omnivores}

To the best of my knowledge, there are, until recently, two surveys that collect information on both cultural consumption and social attitudes and, consequently, just a handful of papers that examine the social attitudes of cultural consumers. Using data from the 1993 General Social Survey (GSS), Bryson (1996) reports that politically intolerant individuals dislike more musical genres; and those with high racism score report more dislikes of those 'genres that are disproportionately liked by Hispanic or Black respondents' (1996, pp. 891-892).

Also using GSS data, DiMaggio (1996, p. 161) shows that 'art-museum visitors are somewhat more secular, trusting, politically liberal, racially tolerant, and open to other cultures and lifestyles ... than are comparable nonvisitors.' These attitudes, according to DiMaggio, suggest 'a distinctly modern disposition, evincing, first, a faith in progress and in scientific (and artistic) authority; and second, an open, cosmopolitan orientation to both people and cultures.'

Using data from 2003-04 Cultural Participation in Flanders survey, Van Eijck and Lievens (2008) study the association between musical consumption 
and attitudes on social integration. They find that 'omnivores are rather concerned with the well-being of others. They are neither isolated nor socially disoriented, but they are not likely to be very individualistic either ... The eclecticism and openness attributed to cultural omnivores do not seem to imply a markedly self-willed attitude' (Van Eijck and Lievens, 2008, p. 235). ${ }^{3}$

If the above findings hold for the UK, we would expect UK's cultural omnivores to be relatively tolerant, cosmopolitan and others-regarding individuals who are more open to new experiences. And since trust is known to correlate with openness (Cawvey et al., 2018), we would also expect omnivores to be more trusting and more likely to take risks in trusting strangers. Some of these expectations can be tested with recent survey data. We have, for example, direct measures of trust and risk-taking. And since, in the UK, support for the EU is arguably an expression of an open, cosmopolitan outlook, we could examine how cultural consumption is associated with stance on Europe and with national identity. Furthermore, we could gauge whether omnivores are more open to new experiences and/or more extravert with relevant measures of the Big Five personality traits. Having said that, prima facie, there seems little reason to expect omnivores to be more (or less) agreeable, conscientious or neurotic than others.

\footnotetext{
${ }^{3}$ There is a third survey called the Cultural Capital and Social Exclusion Survey, which was conducted in the UK in 2003-4. This survey contains six questions on attitudes about cultural consumption, and one question each on the following topics: trade unions, homosexuality, censorship of films and magazines, the relative priority of environment and economic growth, childcare facilities, immigration, higher education fees, law and sentencing, trust, and subjective social class membership. However, these data have not been extensively analysed. Warde et al. (2008, p. 153) report some unadjusted differences between omnivores and non-omnivores on views about cultural consumption. As far as I know, there has not been any analysis of the other attitudinal items. The upshot is that we do not know very much about the social and political attitudes of UK's cultural omnivores.
} 
However, if cultural omnivorousness is, at its core, a form of distinction in the Bourdieusian sense, then we would expect omnivores to be quite statusconscious. In particular, when asked how they see themselves generally, i.e. outside the context of cultural consumption, we would expect education and occupation, the two most important status-conferring attributes (see Chan, 2010, chap. 2), to be especially salient to cultural omnivores.

Since cultural capital is often seen as playing a key role in the reproduction of social class advantages, we will explore just how class-conscious omnivores are, and where they stand on conventional left-right issues, such as income inequality, taxation, and public services. Moreover, as Weakliem (1991) points out, there are two types of 'lefts' in many contemporary societies, we will also examine where cultural omnivores stand on postmaterialist issues such as gender equality, gay rights, and the environment.

\section{Data and analytical strategy}

The data that I use come from the British Household Panel Survey (BHPS) and Understanding Society. BHPS began in 1991 with a nationally representative sample of about 5,500 households. All adult members of these households and their children (when they reach the age of 16) have been followed in annual interviews in subsequent years. After 18 waves, BHPS was superseded in 2009 by a new household panel survey called Understanding Society which has a sample of about 30,000 households and over 54,000 individuals. ${ }^{4}$ As BHPS respondents have been incorporated into the sample

\footnotetext{
${ }^{4}$ More information about BHPS and Understanding Society is available from http://www.iser.essex.ac.uk/bhps and www.understandingsociety.org.uk.
} 
of Understanding Society from wave $2(2010-11),{ }^{5}$ there is, for this group of respondents, quite detailed information over a broad range of topics going back many years.

Wave 2 of Understanding Society contains a set of questions on cultural consumption. My strategy is to relate these data to the attitudinal measures collected in waves 1 and 2 of that survey and, for the original BHPS respondents, also to the attitudinal data in the BHPS from 2005 through 2008. To be clear, the dependent variable of many of the regressions reported below predates the key independent variable, i.e. cultural consumption pattern. For this research strategy to work, I need to assume that individuals have fairly stable cultural consumption habits, at least over the period of several years. Of course, individuals do sometimes change their cultural consumption pattern, say, as a result of becoming a parent. ${ }^{6}$ To the extent that this is the case, the independent variable of interest, i.e. the latent classes of cultural consumption, will have more measurement errors, and its association with social attitudes will be weaker. In other words, this approach is biased against finding statistically significant associations between cultural consumption and social attitudes. Given this, we could be more confident of the significant associations that are actually found.

\footnotetext{
${ }^{5}$ The fieldwork of each wave of Understanding Society takes two calendar years. Thus, wave 1 took place in 2009-10, wave 2 took place in 2010-11, and so on.

${ }^{6}$ Parents of young infants are less likely to take part in cultural consumption of the kinds considered in this paper, quite possibly because they have less time (see Chan, 2010).
} 
Table 1: Percentage of Understanding Society respondents aged 20-64 who have been to music or visual arts events in the past 12 months $(N=28,657)$

\begin{tabular}{llr}
\hline \hline & & $\%$ \\
\hline 1 & Opera/operetta & 4.0 \\
2 & Classical music performance & 7.9 \\
3 & Rock, pop or jazz performance & 29.7 \\
4 & Exhibition or collection of art, photography or sculpture or a & 28.6 \\
& craft exhibition (not craft market) & 7.5 \\
5 & Event which included video or electronic art & 16.5 \\
6 & Street arts or public art display or installation (art in every- & \\
& day surroundings, or an art work such as sculpture that is & \\
& outdoors or in a public place) & 14.2 \\
7 & Carnival or culturally specific festival (for example, Mela, & \\
& Baisakhi, Navrati, Feis) & 41.4 \\
\hline
\end{tabular}

\subsection{Independent variable: latent classes of music and visual arts consumption}

Our independent variable concerns cultural consumption in the domains of music and the visual arts. In wave 2 of Understanding Society, respondents were asked whether in the past 12 months they have been to three kinds of musical events and five types of visual arts events (see Table 1). ${ }^{7}$

Regarding music, items 1 and 2 are conventional highbrow genres; while the very heterogeneous item 3 is not. As regards visual arts, items 4 and 5 are highbrow, with item 5 being perhaps relatively avant-garde. Items 6 and 7 refer to visual arts that are found 'on the street', including, say, sculptures of Henry Moore or Barbara Hepworth, but also street graffiti, and displays of ethnic masks and carvings, batik and embroideries, and other folk

\footnotetext{
${ }^{7}$ To adjust for the complex sampling design of both BHPS and Understanding Society, all results reported in this paper are weighted.
} 
crafts in cultural festivals. I treat these two items as representing 'popular' forms of visual arts. Finally, item 8 is problematic as it lumps museums and galleries together. As Chan and Goldthorpe (2007c, p. 173) observe, 'some museums - for example, natural history, industrial or local or regional museums - while no doubt displaying many objects of visual interest may not contain much in the way of "works of art" as usually understood.' For this reason, many respondents might see item 8 as representing visual arts of a middling kind.

The binary response to these indicators form a 8-way contingency table with 256 (i.e. $2^{8}$ ) cells. Chan and Turner (2017) analyse this table with latent class models and report three latent classes (see Appendix A for details). To elaborate, members of the largest latent class (comprising $58 \%$ of the sample) are least likely of all to attend music or visual art events. Their cultural consumption is largely restricted to one non-highbrow item in each domain, namely, 'rock, pop and jazz' for music and 'museum' for visual arts. Given this, Chan and Turner (2017) call this latent class univores (U). In contrast, members of the smallest latent class ( $14 \%$ of the sample) are, in relative terms at least, avid consumers of music and visual arts of all kinds. Compared to others, members of this latent class are considerably more likely to consume each of the eight items, whether they are highbrow or not. For this reason, this latent class is labelled omnivores $(\mathrm{O})$. Finally, there is a third latent class that is in-between the other two classes both in terms of its size (28\%) and the probability of cultural consumption. Accordingly, Chan and Turner (2017) refer to this latent class as paucivores (P) because 'pauci', meaning few, is an apt description of the modest amount and limited range of cultural 
consumption of those in the second latent class. In the analyses that follow, I use this threefold latent class distinction as the key independent variable.

\subsection{Control variables}

All regression models reported below control for the respondent's age, gender, ethnicity, marital status, education (six levels), household income, the 5-class version of the CASMIN class schema (Erikson and Goldthorpe, 1992), and the social status scale developed by Chan and Goldthorpe (2004). The control variables are taken from the same year as the relevant dependent variable. Table 2 provides some descriptive statistics of the control variables. ${ }^{8}$

\subsection{Dependent variables: social attitudes and person- ality traits}

Altogether, I consider 25 dependent variables taken from waves 15 to 18 (2005-2008) of the BHPS and waves 1 and 2 (2009-10, 2010-11) of Understanding Society. Thematically, they fall into seven domains: (1) trust and risk-taking, (2) the European Union, (3) national and subnational identities, (4) sense of self, (5) subjective social class membership, (6) politics, and (7) the Big Five personality traits.

Before reporting the empirical results, three general remarks are in order. First, there is no good reason to think that cultural consumption is a general cause of social attitudes. It is more likely that cultural consumption and

\footnotetext{
${ }^{8}$ Because of the much larger sample size of Understanding Society and also because of oversampling of ethnic minorities in that survey, five ethnic groups could be distinguished for that survey, namely 'white', 'asian', 'black', 'mixed' and 'others'. For BHPS, I used the binary 'white-non-white' contrast.
} 
Table 2: Descriptive statistics of control variables

\begin{tabular}{|c|c|c|c|c|c|c|}
\hline & \multicolumn{4}{|c|}{ BHPS } & \multicolumn{2}{|c|}{$\begin{array}{l}\text { Understanding } \\
\text { Society }\end{array}$} \\
\hline & 2005 & 2006 & 2007 & 2008 & $2009-10$ & $2010-11$ \\
\hline female & 53.0 & 53.1 & 52.8 & 51.9 & 50.6 & 54.6 \\
\hline non-white & 5.1 & 5.4 & 5.5 & 5.6 & & \\
\hline mixed & & & & & 0.9 & 1.0 \\
\hline $\operatorname{asian}$ & & & & & 3.6 & 4.5 \\
\hline black & & & & & 1.8 & 2.3 \\
\hline other ethnic groups & & & & & 1.9 & 2.3 \\
\hline couple & 72.0 & 72.6 & 72.7 & 71.6 & 55.7 & 52.1 \\
\hline divorced/separated/widowed & 11.0 & 10.1 & 9.7 & 9.7 & 14.1 & 13.2 \\
\hline single & 17.0 & 17.4 & 17.6 & 18.7 & 30.3 & 34.7 \\
\hline no qualification & 11.0 & 9.6 & 8.6 & 7.4 & 18.5 & 19.0 \\
\hline CSE & 6.6 & 6.1 & 6.0 & 5.4 & 8.7 & 8.4 \\
\hline O-levels & 15.4 & 14.7 & 14.3 & 13.7 & 24.6 & 24.6 \\
\hline A-levels & 11.2 & 11.2 & 11.4 & 11.8 & 10.5 & 11.6 \\
\hline further education & 37.0 & 38.6 & 39.7 & 40.9 & 10.9 & 10.5 \\
\hline degree & 18.9 & 19.8 & 20.1 & 20.9 & 26.8 & 25.9 \\
\hline salariat & 39.1 & 42.5 & 43.2 & 43.8 & 41.3 & 42.0 \\
\hline routine non-manual & 24.7 & 22.8 & 22.0 & 21.7 & 12.3 & 14.0 \\
\hline self-employed & 7.5 & 7.0 & 7.1 & 7.0 & 8.9 & 9.2 \\
\hline manual supervisor & 5.7 & 5.3 & 5.5 & 5.3 & 9.3 & 7.9 \\
\hline working class & 23.1 & 22.4 & 22.2 & 22.2 & 28.2 & 26.9 \\
\hline age (mean) & 43.4 & 43.4 & 43.4 & 42.6 & 42.9 & 42.0 \\
\hline age (s.d.) & 12.3 & 12.2 & 12.2 & 11.8 & 12.4 & 12.6 \\
\hline social status (mean) & .01 & .03 & .03 & .04 & .03 & .03 \\
\hline social status (s.d.) & .35 & .36 & .36 & .36 & .36 & .36 \\
\hline log income (mean) & 10.3 & 10.3 & 10.4 & 10.5 & 8.0 & 8.0 \\
\hline log income (s.d.) & .73 & 1.01 & .94 & .85 & .78 & .78 \\
\hline
\end{tabular}

Note: The figures above are percentages, except for age, social status and log-income 
certain attitudes and personality traits tend to go together. So the results reported below should be interpreted as statistical associations rather than causal relationships (see also DiMaggio, 1996, p. 174).

Second, given the large number of dependent variables considered, I present the key results graphically (relegating the tables of regression coefficients to Appendix B). Specifically, I report the predicted value of each dependent variable (with the $95 \%$ confidence interval) under six hypothetical scenarios. The scenarios are defined jointly by cultural consumption (whether the respondents are $\mathrm{U}, \mathrm{P}$ or $\mathrm{O}$ ) and educational attainment (whether they are university graduates or have no qualifications). ${ }^{9}$ Given that 'education is clearly the most powerful predictor' for a wide range of attitudes and behaviour (Davis, 1982, p. 585), I use the largest educational contrast (i.e. between university degree and no qualification) as a benchmark against which the differences among $\mathrm{U}, \mathrm{P}$ and $\mathrm{O}$ are compared.

Third, in evaluating the regression results, we need to consider not just whether the parameters are statistically significant, but also their substantive magnitude. To this end, I have, in addition to using education as a benchmark, standardised the dependent variables of the OLS regressions (i.e. their mean and variance are normed to equal zero and one respectively). This

\footnotetext{
${ }^{9}$ The predicted values are computed as follows. I first assume that all respondents are university graduates and omnivores, while all other covariates take on their actual values. I then calculate the predicted value of the dependent variable for each respondent, and the predicated values are then averaged. In other words, this is the mean of the individual predictions, not the predicted value evaluated at the mean of the covariates. Other combinations of education and cultural consumption are computed in an analogous way. Also, note that (1) there is no interaction term between education and cultural consumption in the model upon which the predicted probabilities are calculated, and (2) six educational levels are distinguished in the regression models; but to avoid cluttering up the graphs, I only show the largest contrast between university graduates and individuals with no qualification.
} 
means that the OLS estimates can be read as fractions of standard deviation of the relevant dependent variable.

\section{Results}

\subsection{Trust and risk-taking}

Let us start with a couple of questions on trust and risk-taking. In wave 1 of Understanding Society, respondents were asked: 'Generally speaking would you say that most people can be trusted, or that you can't be too careful in dealing with people?' Overall, just over one third (36\%) of the respondents believe that 'most people can be trusted.' But there is considerable variation in how trusting the respondents are by educational attainment and by cultural consumption. The left panel of Figure 1 shows that university graduates are significantly and substantially more trusting than individuals without qualifications (compare the estimates in the top group with the corresponding estimates in the bottom group). The same is true of omnivores and paucivores as compared to univores (compare the estimates within each group). The magnitude of these associations is quite large. To illustrate, half of graduate omnivores believe that most people can be trusted, compared to about one third $(35 \%)$ of omnivores without qualifications, $40 \%$ of graduate univores, and $26 \%$ of univores without qualifications.

In the same survey, respondents were also asked: 'Are you generally a person who is fully prepared to take risks or do you try to avoid taking risks?' The response categories to this question form a scale that ranges from 0 to 

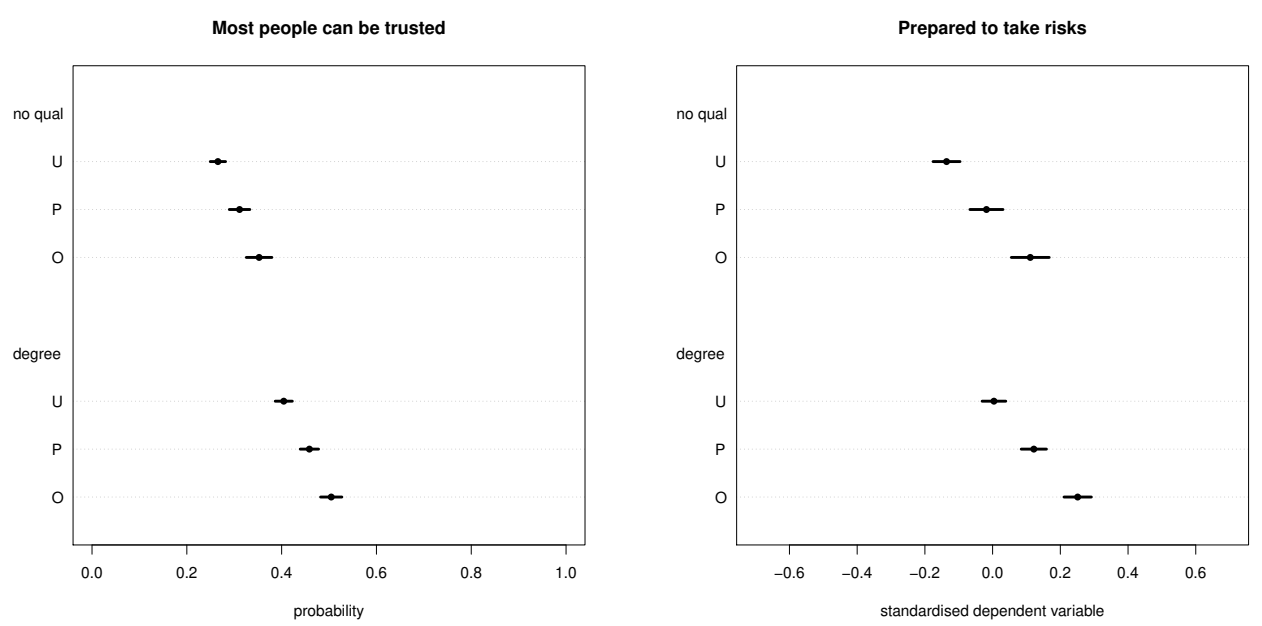

Figure 1: Predicted probabilities (with 95\% confidence intervals) of risktaking and trust by education and cultural consumption

10, with higher values denoting a more risk-taking disposition. The right panel of Figure 1 shows that omnivores and paucivores are also more likely to take risks than univores and, again, the magnitude of these differences is quite large. Other things being equal, omnivores are about a quarter (.25) of a standard deviation more disposed to taking risks than univores, while graduates are about one-sixth (.16) of a standard deviation more risktaking than people with no qualifications. ${ }^{10}$ These results are consistent with those of DiMaggio (1996) in that omnivores and paucivores are more risktaking and trusting than univores. Since, as noted above, trust is correlated with openness (Cawvey et al., 2018), these results suggest that paucivores and omnivores are significantly more open than univores. Perhaps of equal importance is the finding that these associations are of comparable magnitude

\footnotetext{
${ }^{10}$ To make the prose less clunky, I drop the reference to 'univores' and 'people without qualifications'. Unless indicated otherwise, readers can assume that the parameters of omnivores and paucivores are compared to univores, and that of graduates is compared to people without qualifications.
} 

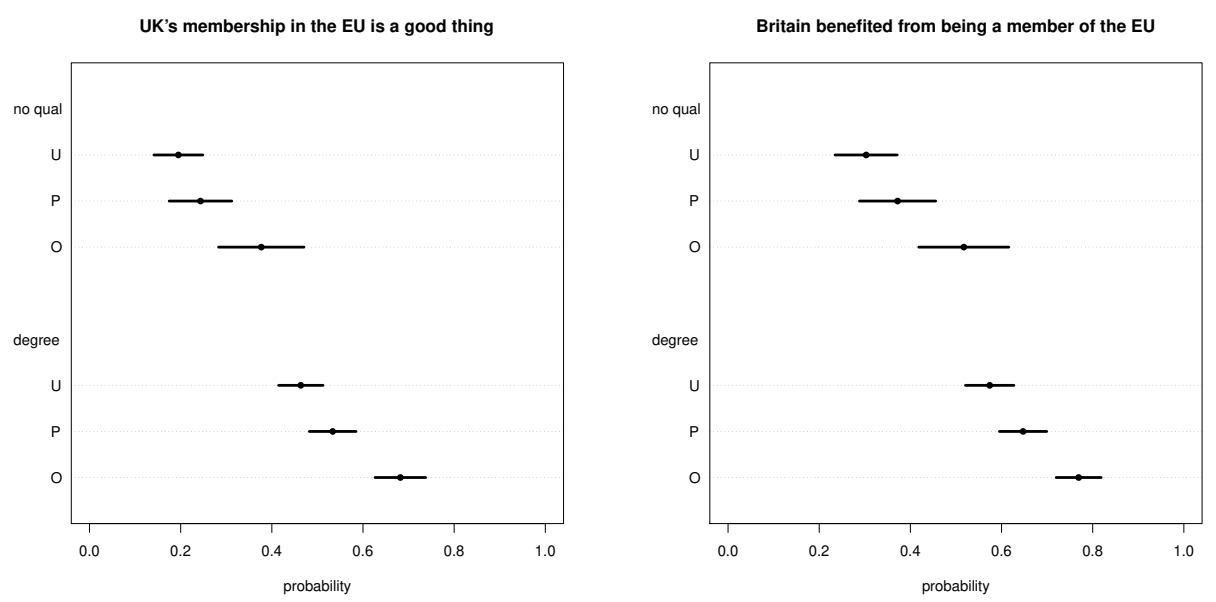

Figure 2: Predicted probabilities (with 95\% confidence intervals) of views about the European Union by education and cultural consumption

to that of the largest educational contrast. ${ }^{11}$

\subsection{The European Union}

As is clear from the $2016 \mathrm{EU}$ referendum, Britons are, on the whole, quite sceptical of the European Union. In 2006, BHPS respondents were asked the following questions: (1) 'Generally speaking, do you think that Britain's/the UK's membership of the European Union is a good thing, a bad thing or is it neither good or bad?', (2) 'Taking everything into consideration, would you say that Britain/the UK has on balance benefited or not from being a member of the European Union?'

Just over a third $(36 \%)$ of the respondents think that EU membership

\footnotetext{
${ }^{11}$ There is a third question which asks 'Are you generally a person who is fully prepared to take risks in trusting strangers or do you try to avoid taking such risks?' Since the results from this third question is very similar to those reported here, and given the space constraint, I do not include them in the paper. The same is true of many other domains discussed below. Details are available from the author on request.
} 
is a good thing, ${ }^{12}$ and under half (45\%) think that the UK has on balance benefited from being in the EU. But omnivores, paucivores, and university graduates are more pro-EU than their respective reference group. The left panel of Figure 2 shows that $68 \%$ of graduate omnivores think that UK's membership in the EU is a good thing, compared to $38 \%$ of omnivores without qualifications, $46 \%$ of graduate univores and $19 \%$ of univores with no qualifications. These are large differences. A similar pattern holds for the question of whether the UK has benefited from the EU (right panel).

In the wake of the $2016 \mathrm{EU}$ Referendum, many commentators point to the age and educational gradients in the Brexit vote (e.g. Goodwin and Heath, 2016). Our result shows that net of age, education and, indeed, all other covariates in the model, the differences between omnivores, paucivores and univores are just as substantial. Euroscepticism in the UK has many dimensions. But to the extent that it reflects an insular, 'keep the foreigners at bay' mindset, the results of this section, again consistent with DiMaggio (1996), suggest that omnivores and paucivores have a more cosmopolitan outlook.

\subsection{National and subnational identities}

British people's attitudes about the EU is partly a matter of national identity: 'just how European are we?' This suggests a tension between national and supranational identities. Similar tension might be found between national and subnational identities. That is to say, Britons might identify with the UK as a whole, and/or with one of its four constituent countries: England, Wales,

\footnotetext{
${ }^{12} \mathrm{I}$ have dichotomised the response categories, contrasting the first category against the second and the third categories.
} 

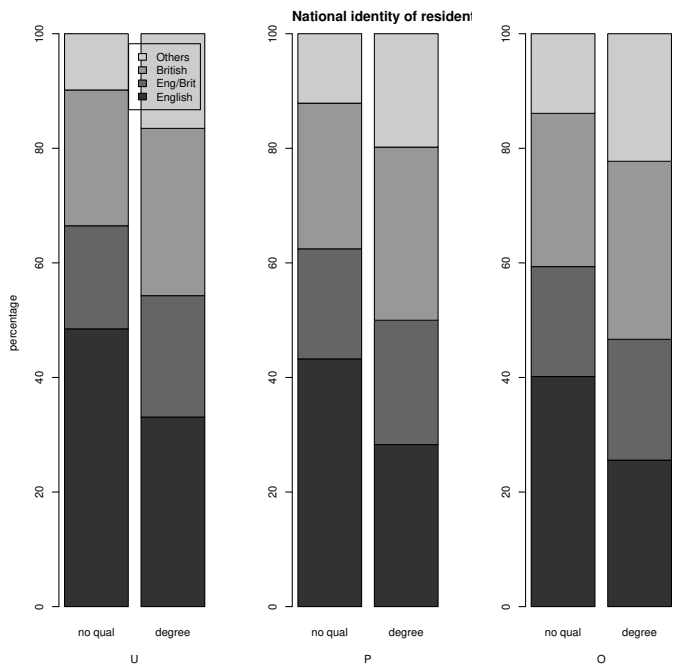

Figure 3: Predicted probabilities of national and subnational identity of residents in England by education and cultural consumption

Scotland and Northern Ireland. Given the popularity of some nationalist parties in the UK and especially the strong showing of the Scottish National Party in both the 2014 referendum on Scottish independence and the 2015 general election, this is a potent political issue.

In wave 1 of Understanding Society, respondents were asked 'Looking at this card, what do you consider your national identity to be? You may choose as many or as few as apply.' As this question allows respondents to report multiple identities, I construct a four-fold typology of national and subnational identities for residents of England: ${ }^{13}$ (1) English, (2) British, (3) British and English, and (4) Others. In this sample, about $40 \%$ of the residents in England identify themselves as English only; just over a quarter (27\%) as British; one fifth (21\%) as both British and English; and one-eighth $(13 \%)$ choose other categories or other combinations of categories.

\footnotetext{
${ }^{13}$ Residents of England account for $84 \%$ of the UK population.
} 
Using this fourfold typology as the dependent variable in a multinomial logistic regression, it turns out that graduates are more likely to identify themselves as British, British and English, or even Others rather than just English. The same holds for paucivores and omnivores as compared with univores. Figure 3 shows that these associations are, again, large in magnitude: $48 \%$ of those living in England identify themselves as English only if they are univores without qualifications; compared to $33 \%$ of graduate univores; $40 \%$ of omnivores without qualifications; and $26 \%$ of graduate omnivores. ${ }^{14}$

The previous section shows that graduates, paucivores and omnivores are more supportive of the supranational European Union. When asked to choose between national and subnational identities, they also tend to eschew the more parochial subnational identities and go for the broader British identity. This lends further support to the view that omnivores and paucivores are more cosmopolitan in their outlook. ${ }^{15}$

\footnotetext{
${ }^{14}$ I have repeated the analysis for residents in Scotland, Wales and Northern Ireland. Subnational identities are more common in Wales, Northern Ireland and, especially, Scotland, reflecting the strength of nationalist sentiments in those parts of the UK. Using the same multinomial logit model, I find similar results for Scotland, except that neither education nor cultural consumption predicts whether Scottish residents see themselves as British and Scottish rather than just Scottish. In Wales, cultural consumption is unrelated to national identities. But education matters for the contrasts of British v Welsh and Others v Welsh. The result for Northern Ireland is quite different in that neither education nor cultural consumption predicts national identity. This might be related to the history of violent conflict between the protestant and catholic communities there, as a result of which national and subnational identities have acquired a particularly negative salience. That is to say, identifying yourselves as British, Irish or Northern Irish might, for some, carry a sectarian connotation.

${ }^{15}$ The question of identity is also especially salient to ethnic minorities. In wave 1 of Understanding Society, all respondents with a non-'White British' father were asked: 'How important is being [father's ethnic group] to you?' In addition, members of the ethnic minority boost sample and the general population comparison sample were asked: 'Most people who live in the UK may think of themselves as being British in some way. ... how important is being British to you?' It turns out that graduates, paucivores and omnivores tend to attach less importance to their father's ethnic identity. They are also less likely to think that 'being British' (when considered on its own) is important. These
} 


\subsection{Sense of self}

In Wave 2 of Understanding Society, respondents were asked: 'We'd like to know how important various things are to your sense of who you are. Please think about each of the following and tick the box that indicates whether it is very important, fairly important, not very important or not at all important to your sense of who you are.' In the analyses below, I have dichotomised the responses, contrasting the first two categories against the last two.

There is a good deal of variation in the response given. Almost everyone $(95 \%)$ attach importance to their family, followed by their profession $(75 \%)$, age $(72 \%)$, gender $(65 \%)$, education $(65 \%)$, ethnicity $(43 \%)$ and, finally, politics which is considered important by only $30 \%$ of the respondents. Against this overall ranking, graduates, paucivores and omnivores are quite distinctive in their reply. For example, they are significantly less likely to attach importance to their family or ethnicity, though, as the top panels of Figure 4 show, these differences are quite small in magnitude. Moreover, although about three quarters of the respondents consider their profession or age as important aspects of who they are, these two factors are not especially salient for graduates or cultural consumers. What is important to cultural omnivores is politics, even though this item ranks bottom for the sample as a whole. The bottom-left panel of Figure 4 shows that $44 \%$ of graduate omnivores think that their politics is important to them, compared to $30 \%$ of graduates univores and $36 \%$ of omnivores without qualifications.

results confirm the association between omnivorousness and a more open, cosmopolitan attitude, the magnitude of which is, again, comparable to the largest net difference by educational attainment. Details are available from the author. 

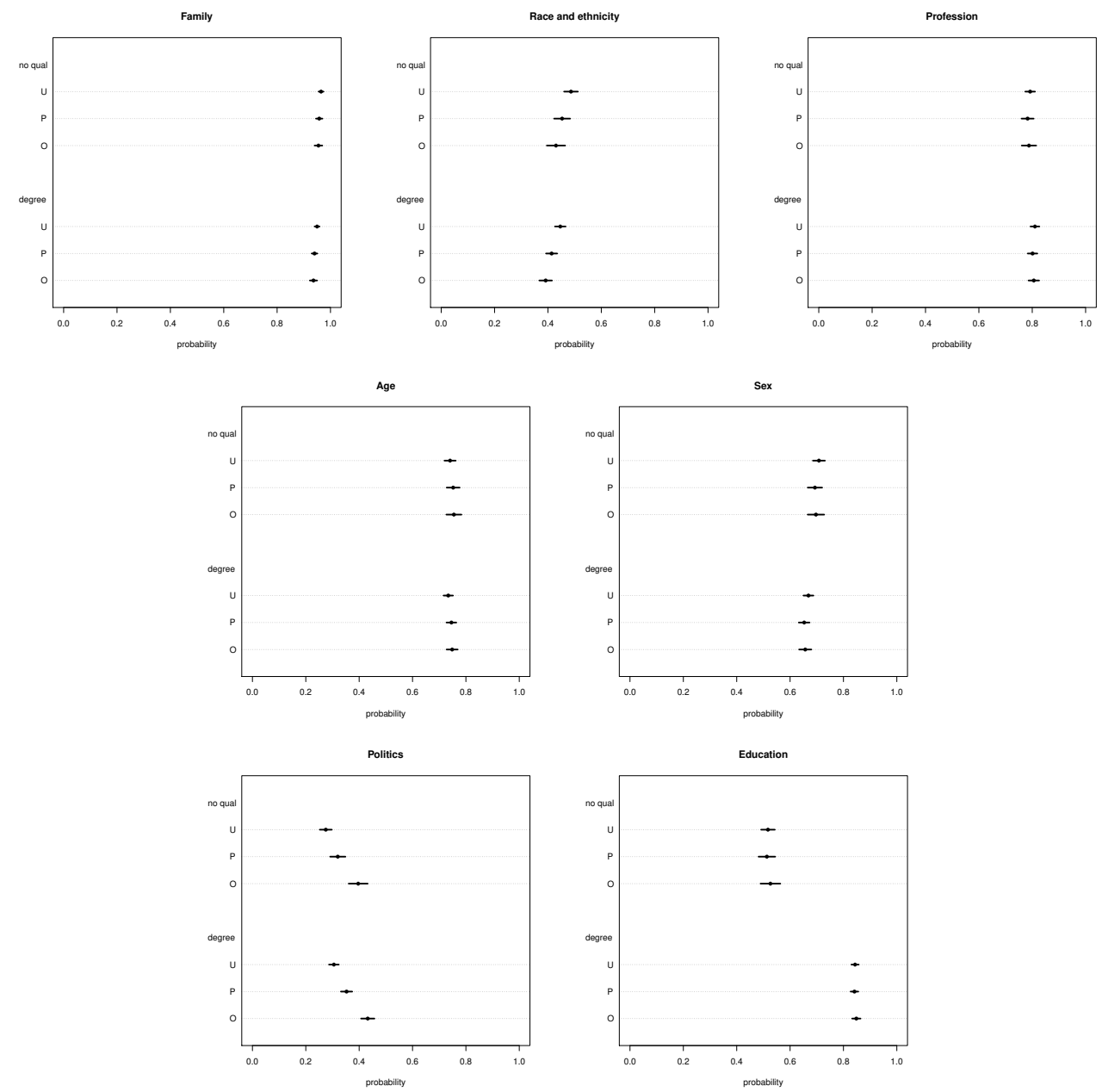

Figure 4: Predicted probabilities (with 95\% confidence intervals) of "what is important to the sense of who you are' by education and cultural consumption 

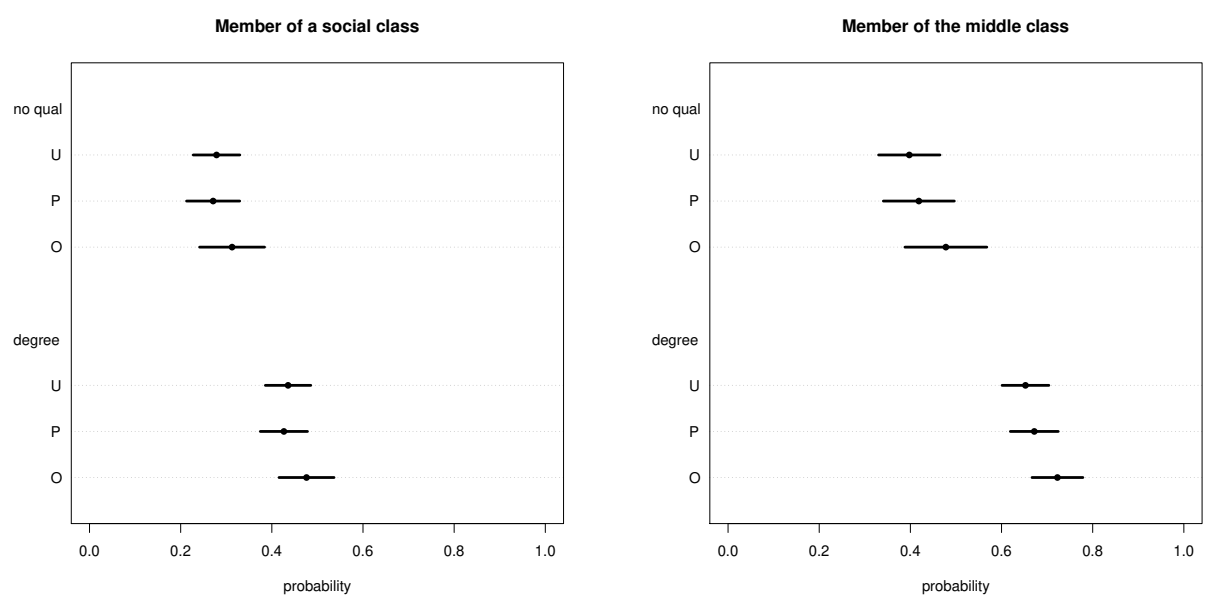

Figure 5: Predicted probabilities (with 95\% confidence intervals) of identification with a social class (left panel) and being the 'middle class' (right panel) by education and cultural consumption

Not surprisingly, education is especially important to graduates' sense of self, and the magnitude of this association is very large (see bottom-right panel of Figure 4). Compared to univores, however, omnivores or paucivores do not set great store by education. And since education and occupation are the most important status-conferring attributes (Chan, 2010, chap. 2), the evidence of this section suggests that, compared to univores, omnivores and paucivores are not especially status-conscious individuals.

\subsection{Subjective social class membership}

In 2005, BHPS respondents were asked: 'Do you think of yourself as belonging to any particular social class?' Just over a third (36\%) of the respondents say 'yes'. And although university graduates are significantly and substantially more likely to do so, there is no evidence that cultural consumption matters in this regard (see the left panel of Figure 5). 
Regardless of their answer to the previous question, respondents were then asked to name the social class that they belong to: '(If you had to choose) which social class would you say you belong to?' Just under half (46\%) of the respondents call themselves middle class rather than working class. ${ }^{16}$ As might be expected, graduates are much more likely to see themselves as middle class, as are omnivores compared with univores. But although the contrast between omnivores and univores is statistically significant, its magnitude is relatively small. As the right panel of Figure 5 shows, $72 \%$ of graduate omnivores see themselves as middle class, compared to $65 \%$ of graduate univores, $47 \%$ of omnivores without qualifications, and $40 \%$ of univores without qualifications. Recall that it is only when prompted that omnivores would say that they belong to the middle class. Overall, it seems fair to say that so far as subjective social class membership is concerned, its association with education is stronger than that with cultural consumption.

\subsection{Politics: distributional and post-materialist}

In wave 2 of Understanding Society, respondents were asked: 'How interested would you say you are in politics?' About four in ten (42\%) of all respondents say that they are very or fairly interested. But there are large differences in the response to this question by education and cultural consumption. The top-left panel of Figure 6 shows that almost three quarters (74\%) of graduate omnivores are interested in politics, compared to about half of omnivores with no qualifications $(52 \%)$ or graduate univores $(50 \%)$, and a quarter $(28 \%)$ of

\footnotetext{
${ }^{16}$ I dichotomise the seven response categories to this question, combining lower middle class, middle class, upper middle class, and upper class as middle class, and grouping lower working class, working class, and upper working class as working class.
} 

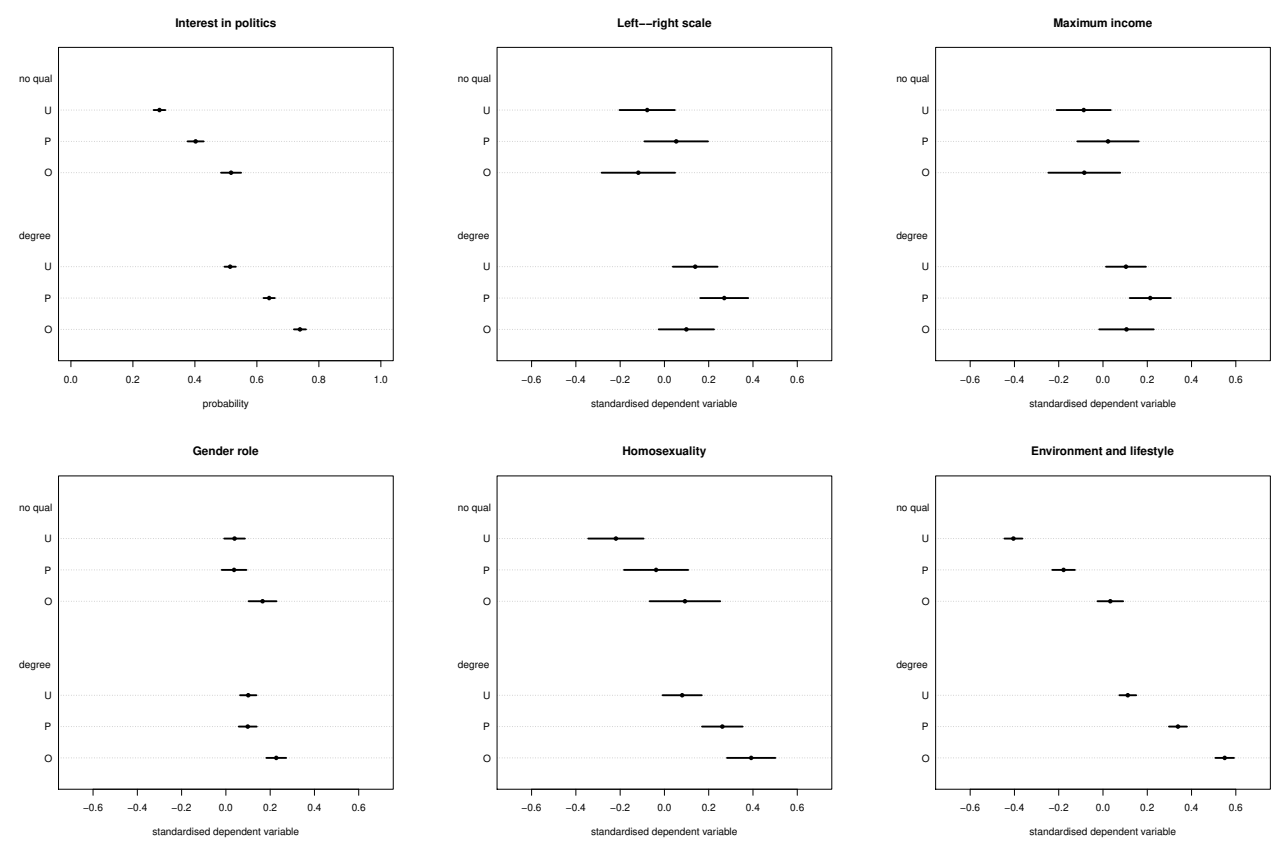

Figure 6: Predicted probabilities (with 95\% confidence intervals) of interest in politics, stances on left-right issues and postmaterialist issues by education and cultural consumption

the univores without qualifications. These results confirm that politics is important to omnivores. But what kinds of political issues exercise them? How do we characterise their politics?

In wave 17 of the BHPS, there are six questions that tap opinions on the distribution of wealth, public services, trade unions, etc (see the Appendix for details). I use these to form an additive scale on 'left-right' political attitudes, with higher values denoting more right-wing views. The top-centre panel of Figure 6 shows that graduates are more right-wing than individuals with no qualifications, as are paucivores compared with univores. But omnivores are not different from the univores on the left-right scale. If anything, omnivores are less 'right-wing' than paucivores. Broadly the same pattern is found in 
relation to a question on income inequality from wave 16 of the BHPS: 'The government should place an upper limit on the amount of money that any one person can make,' where higher values denote more right-wing views (see top-right panel of Figure 6).

Turning from bread-and-butter issues to postmaterialist ones, Wave 2 of Understanding Society contains a set of five questions on women's role at home and in the workplace (see the Appendix for details), which I use to form an additive scale on gender role, with higher values denoting more egalitarian views. The bottom-left panel of Figure 6 shows that graduates are significantly more egalitarian on gender role than individuals with no qualifications, as are omnivores compared to paucivores or inactives. Moreover, the magnitude of the ' $\mathrm{O} v \mathrm{U}$ ' and ' $\mathrm{O} v \mathrm{P}$ ' contrasts are twice as large as that of the degree-no qualification contrast.

Then there is a BHPS question in 2008 on whether 'homosexual relationships are always wrong.' The response to this question is coded in such a way that higher values represent more liberal views. The bottom-centre panel of Figure 6 shows that education and cultural consumption are both associated with more liberal views on homosexuality. Specifically, omnivores are about a third of a standard deviation more liberal than univores, as are university graduates compared to people with no qualifications.

Finally, in wave 1 of Understanding Society, there is a set of 14 questions on the environment and climate change. I use these items to form an additive scale, with higher values representing greener or more environmentally friendly attitudes. The bottom-right panel of Figure 6 shows that graduates are about one half of a standard deviation greener than people with no qual- 

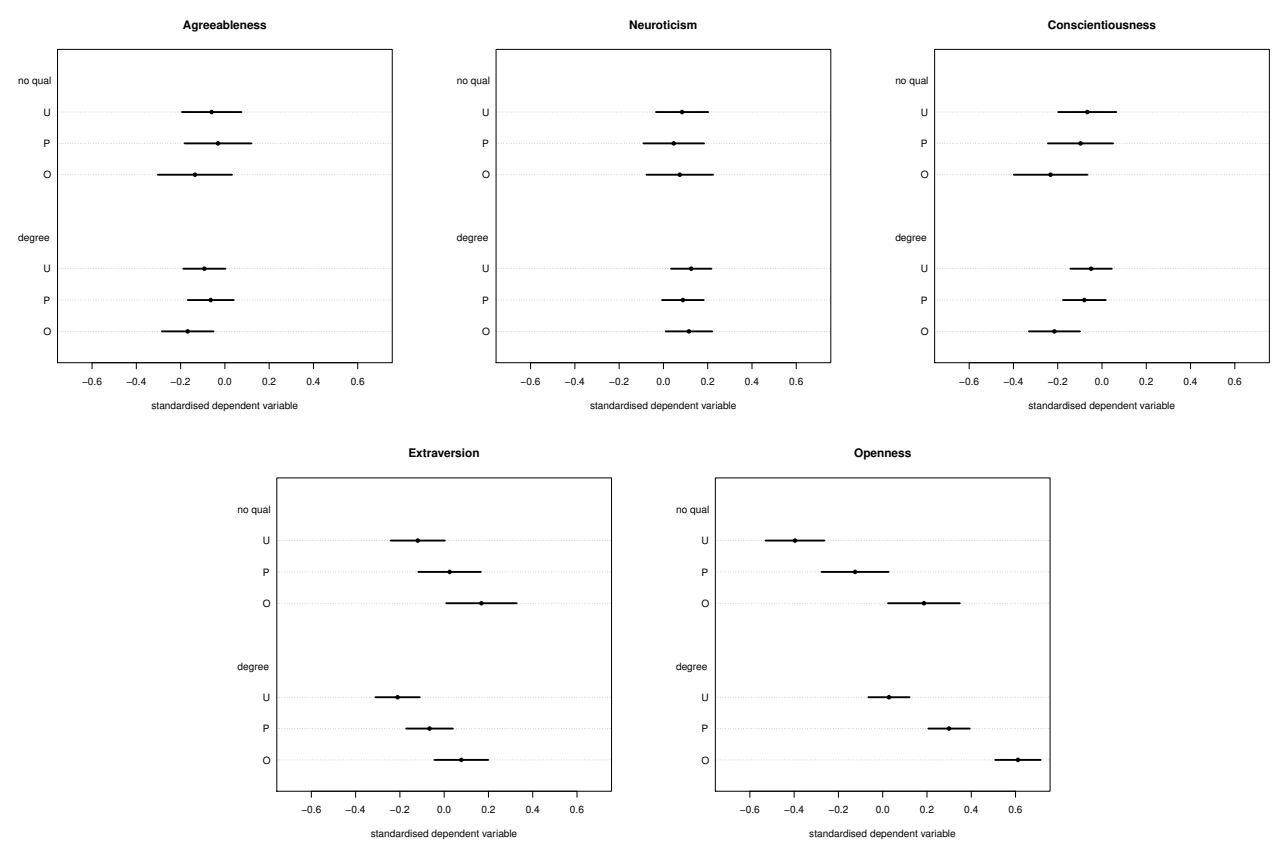

Figure 7: Predicted scores (with 95\% confidence intervals) of Big Five personality traits by education and cultural consumption

ifications. The same is also true of omnivores when compared to univores. Overall, it seems fair to say that the politics of cultural omnivores is notable not so much for their position on the left-right scale, but rather for their liberal views on postmaterialist issues.

\subsection{Big Five personality traits}

In wave 15 of the BHPS, there is a set of 15 questions that measure the Big Five personality traits (Gosling et al., 2003). The panels in the top row of Figure 7 show that, net of other covariates, paucivores and omnivores are not different from univores on agreeableness or neuroticism; but omnivores are less conscientious than univores.

In line with our expectation, omnivores and paucivores score significantly 
higher than univores on 'extraversion' and 'openness to experience'. These net differences are quite large: compared to the univores, omnivores are over a quarter (.29) of a standard deviation more extravert and over half (.57) of a standard deviation more open to new experiences. These results are, in part, consistent with those reported by Kraaykamp and van Eijck (2005, p. 1686) who argue that 'openness turned out to be the most important personality determinant of media preferences and cultural participation ... [pertaining to] not only highbrow activities, but also the reading of detective novels or the visiting of pop concerts.'

\section{Summary and discussion}

In this paper, I use linked data from the British Household Panel Survey and Understanding Society to explore the subjective meaning of cultural omnivorousness. There is strong evidence that omnivores, paucivores and univores in the UK are quite different in their social and political attitudes. Over a wide range of issues, there are statistically significant and substantively large differences among them. The differences are especially notable between omnivores and univores, with paucivores usually (though not always) taking up an intermediate position.

Omnivores are more trusting and risk-taking. They are more supportive of the supranational European Union, and they tend to eschew subnational identities. Together, these results suggest that omnivores have a more open and cosmopolitan outlook. Omnivores are more liberal on gender role attitudes and on homosexuality, and they are greener when it comes to the 
environment and climate change. Overall, omnivores are more liberal on postmaterialist issues.

These results are largely consistent with those reported for the US by DiMaggio (1996). But as this point has not been brought out clearly in previous research, it bears repeating just how strong many of these associations are. Davis (1982, p. 585) points out that 'education is clearly the most powerful predictor' for a wide range of outcome variables. ${ }^{17}$ So it is quite striking that in many cases the omnivore parameter is of comparable magnitude to the degree parameter.

Omnivores are politically more engaged. But social class does not appear to be at the forefront of their mind when they were asked about class membership. In this sense, omnivores are not especially 'class-conscious'. And although university graduates and paucivores are more right-wing, omnivores are not different from univores on distributional issues. This result is consistent with the finding of Chan and Goldthorpe (2007a) that 'left-right' attitudes and 'libertarian-authoritarian' attitudes have different social bases. Specifically, 'left-right' attitudes are linked to social class rather than social status, and the opposite is true for 'libertarian-authoritarian' attitudes. As cultural omnivorousness has a net association with social status, but not with social class (Chan and Goldthorpe, 2005, 2007b,c), it makes sense that omnivores are not particularly left-wing or right-wing. Put differently, cultural omnivorousness is orthogonal to social class in the classical Weberian sense.

\footnotetext{
${ }^{17}$ Kingston et al. (2003, p. 53) observe that 'education is a great independent variable ...almost as a reflex, researchers include educational attainment as one of the normal "suspects" in multivariate analyses of almost any outcome of sociological interest. The common result is a significant increase in $R^{2}$ or its cognates and a decrease in the apparent "net effects" of other variables.'
} 
Furthermore, when asked what is important to their sense of who they are, omnivores do not attach particular significance to their profession or education, the two most important status-conferring attributes (Chan, 2010, chap. 2). There is certainly a status gradient in cultural consumption. But omnivores are not more status-conscious than univores. What set omnivores apart is that, in terms of personality traits, they are more extravert and more open to new experiences.

Returning to the research question that motivates this paper: what does it mean to be culturally omnivorous? As noted in the introduction, there are two views on this matter. Under the first view, omnivores are essentially tolerant, cosmopolitan individuals who are generally open to different cultural styles. Under the second view, cultural omnivorousness is an expression of distinction, a new form of cultural capital, and a novel way to demonstrate cultural and social superiority. Having considered the evidence drawn from the BHPS and Understanding Society, it seems to me that the first view receives far more empirical support than does the second. Moreover, qualitative research from the UK also supports this interpretation. Based on thirty qualitative interviews, Warde et al. (2007, p. 158) conclude that 'the evidence of our interviews is certainly that omnivorousness accompanies tolerance; there was no evidence of the drawing of cultural boundaries to exclude other social groups, and few indications of snobbishness when expressing personal cultural tastes.' Similarly, Bennett et al. (2009, p. 66) maintain that 'those who were culturally engaged did not articulate a clear sense of cultural superiority.' Indeed, they 'find no one remotely corresponding to the figure of the snob ... These observations imply dynamics [that are] different from those 
described by Bourdieu' (Bennett et al., 2009, pp. 70-71).

Given the above, it would be unjustified to regard cultural omnivorousness as the symbolic expression of class domination or of status competition. Instead, it might be more useful to think along the following line. Some individuals are more open, tolerant and cosmopolitan than others. Such dispositions, which might be cultivated by education, then find expression in different social domains, for example, as liberal tolerance over gender roles and sexual morality, as a more cosmopolitan stance over national identities or Europe, as omnivorousness in cultural consumption, and so on.

This view has obvious affinity with the postmaterialism thesis. Inglehart (2008) argues that with economic development, the need to secure basic material resources for survival becomes less pressing. This then leads to a pervasive cultural change, through cohort replacement, from materialist to postmaterialist values in developed societies. Inglehart identifies two dimensions of postmaterialist values, namely self-expression (as opposed to survival) and secular-rational (as opposed to traditional) values. Although the correspondence is not exact, our discussion of trust, gender role, the environment, and homosexuality speaks to the self-expression dimension, and our discussion of national and ethnic identities addresses the secular-rational dimension.

There is no need for us to accept the postmaterialism argument in full, not least because affluence alone probably does not account for the historical emergence of cultural omnivores (see Peterson and Kern, 1996, pp. 904906). But the similarity between omnivorousness and postmaterialist values is, in some respects, quite striking. It seems reasonable to claim that cultural 
omnivorousness is relatively autonomous from both class hierarchy and status rivalry. As a corollary, I expect omnivores to be more engaged with identity politics than with distributional conflicts of a bread-and-butter kind.

Note that this view is consistent with the fact that cultural consumption is socially stratified. For example, it remains the case that omnivores are much more commonly found among individuals in advantaged social positions, e.g. university graduates. But we should also keep in mind that the majority of graduates are not omnivores. To be concrete, in the Understanding Society sample, just $2 \%$ of those without qualifications are omnivores, and the share of omnivores rises monotonically with educational attainment. But even among university graduates, only a quarter (26\%) are omnivores. Education, social status and, in some instances, income are, indeed, powerful social forces which structure cultural consumption. But among those in advantaged position, it is those with a cosmopolitan and tolerant outlook, those who are extravert and open to new experiences who become omnivorous.

\section{References}

Alderson, A. S., Junisbai, A., and Heacock, I. (2007). Social status and cultural consumption in the United States. Poetics, 35(2/3), 191-212.

Bauman, Z. (1988). Freedom. Open University Press, Milton Keynes.

Bellavance, G. (2008). Where's high? Who's low? What's new? Classification and stratification inside cultural "Repertoires". Poetics, 36, 189-216. 
Bennett, T., Savage, M., Silva, E., Warde, A., Gayo-Cal, M., and Wright, D. (2009). Culture, Class and Distinction. Routledge, London.

Bourdieu, P. (1984). Distinction: A Social Critique of the Judgement of Taste. Routledge \& Kegan Paul, London.

Bryson, B. (1996). "Anything but Heavy Metal": symbolic exclusion and musical dislikes. American Sociological Review, 61(5), 884-899.

Bunting, C., Chan, T. W., Goldthorpe, J., Keaney, E., and Oskala, A. (2008). From indifference to enthusiasm: patterns of arts attendance in England. Research report, Arts Council England, London.

Cawvey, M., Hayes, M., Canache, D., and Mondak, J. J. (2018). Biological and psychological influences on interpersonal and political trust. In E. M. Uslaner, editor, The Oxford Handbook of Social and Political Trust. Oxford University Press.

Chan, T. W., editor (2010). Social Status and Cultural Consumption. Cambridge University Press, Cambridge.

Chan, T. W. and Goldthorpe, J. H. (2004). Is there a status order in contemporary British society? Evidence from the occupational structure of friendship. European Sociological Review, 20(5), 383-401.

Chan, T. W. and Goldthorpe, J. H. (2005). The social stratification of theatre, dance and cinema attendance. The Cultural Trends, 14(3), 193212. 
Chan, T. W. and Goldthorpe, J. H. (2007a). Class and status: the conceptual distinction and its empirical relevance. American Sociological Review, 72(4), 512-532.

Chan, T. W. and Goldthorpe, J. H. (2007b). Social stratification and cultural consumption: Music in England. European Sociological Review, 23(1), 119.

Chan, T. W. and Goldthorpe, J. H. (2007c). Social stratification and cultural conumption: the visual arts in England. Poetics, 35(2/3), 168-190.

Chan, T. W. and Turner, H. (2017). Where do cultural omnivores come from: the implications of educational mobility for cultural consumption. European Sociological Review, 33(4), 576-589.

Coulangeon, P. (2017). Cultural openness as an emerging form of cultural capital in contemporary France. Cultural Sociology, 11(2), 145-164.

Davis, J. A. (1982). Achievement variables and class cultures: family, schooling, job, and forty-nine dependent variables in the cumulative gss. American Sociological Review, 47, 569-586.

DiMaggio, P. (1996). Are art-museum visitors different from other people? The relationship between attendance and social and political attitudes in the United States. Poetics, 24(2-4), 161-180.

Erikson, R. and Goldthorpe, J. H. (1992). The Constant Flux: A Study of Class Mobility in Industrial Societies. Clarendon Press, Oxford. 
Giddens, A. (1991). Modernity and Self-identity: Self and Society in the Late Modern Age. Polity, Cambridge.

Glevarec, H. and Pinet, M. (2017). Is cultural eclecticism axiological and a new mark of distinction? Cultural diversification and social differentiation of tastes in France. Cultural Sociology, 11(2), 188-216.

Goodwin, M. J. and Heath, O. (2016). The 2016 Referendum, Brexit and the left-behind: an aggregate-level analysis of the result. Political Quarterly, $87(3), 323-332$.

Gosling, S. D., Rentfrow, P. J., and Swann, Jr, W. B. (2003). A very brief measure of the big-five personality domains. Journal of Research in Personality, 37, 504-528.

Inglehart, R. (2008). Changing values among Western publics from 1970 to 2006. West European Politics, 31(1-2), 130-146.

Jenkins, R. (1992). Pierre Bourdieu. Routledge, London.

Khan, S. R. (2011). Privilege: The Making of an Adolescent Elite at St. Paul's School. Princeton University Press, Princeton.

Kingston, P. W., Hubbard, R., Lapp, B., Schroeder, P., and Wilson, J. (2003). Why education matters. Sociology of Education, 76, 53-70.

Kraaykamp, G. and van Eijck, K. (2005). Personality, media preferences, and cultural participation. Personality and Individual Differences, 38, 16751688. 
Lamont, M. and Molnár, V. (2002). The study of boundaries in the social sciences. Annual Review of Sociology, 28, 167-195.

López-Sintas, J. and García-Álvarez, E. (2002). Omnivores show up again: the segmentation of cultural consumers in Spanish social space. European Sociological Review, 18(3), 353-368.

Ollivier, M. (2008). Modes of openness to cultural diversity: humanist, populist, practical, and indifferent. Poetics, 36, 120-147.

Peterson, R. A. (1992). Understanding audience segmentation: from elite and mass to omnivore and univore. Poetics, 21(4), 243-258.

Peterson, R. A. (2005). Problems in comparative research: the example of omnivorousness. Poetics, 33, 257-282.

Peterson, R. A. and Kern, R. M. (1996). Changing highbrow taste: from snob to omnivore. American Sociological Review, 61(5), 900-907.

Peterson, R. A. and Simkus, A. (1992). How musical tastes mark occupational status groups. In M. Lamont and M. Fournier, editors, Cultivating Differences: Symbolic Boundaries and the Making of Inequality, chapter Seven, pages 152-186. University of Chicago Press, Chicago.

Prior, N. (2005). A question of perception: Bourdieu, art and the postmodern. British Journal of Sociology, 56(1), 123-139.

Roose, H., Van Eijck, K., and Lievens, J. (2012). Culture of distinction or culture of openness? Using a social space approach to analyze the social structuring of lifestyles. Poetics, 40, 491-513. 
Van Eijck, K. (2001). Social differentiation in musical taste patterns. Social Forces, 79(3), 1163-1184.

Van Eijck, K. and Lievens, J. (2008). Cultural omnivorousness as a combination of highbrow, pop, and folk elements: the relation between taste patterns and attitudes concerning soical integration. Poetics, 36, 217-242.

Warde, A., Wright, D., and Gayo-Cal, M. (2007). Understanding cultural omnivorousness: or, the myth of the cultural omnivore. Cultural Sociology, $\mathbf{1}(2), 143-164$.

Warde, A., Wright, D., and Gayo-Cal, M. (2008). The omnivorous orientation in the UK. Poetics, 36, 148-165.

Weakliem, D. L. (1991). The two lefts? occupation and party choice in France, Italy, and the Netherlands. American Journal of Sociology, 96(6), $1327-1361$. 


\section{A Latent class analysis}

The top panel of Table 3 reports the goodness of fit statistics of latent class models fitted to the contingency table formed with the eight items shown in Table 1. None of the models achieves a satisfactory fit with the data by the conventional criterion of $5 \%$ type I error. But given the very large $N$ of 28,657, I accept model 4 as providing an adequate summary of the data.

Table 3: Goodness of fit statistics of latent class models

\begin{tabular}{crrrrrr}
\hline \hline model & \# latent class & $G^{2}$ & $d f$ & $p$ & $\mathrm{BIC}$ & $\Delta$ \\
\hline 1 & 1 & 27788.83 & 247 & .000 & 25255.74 & .000 \\
2 & 2 & 2926.49 & 238 & .000 & 485.69 & .046 \\
3 & 3 & 1587.14 & 229 & .000 & -761.36 & .121 \\
4 & $3^{*}$ & 490.86 & 223 & .000 & -1796.10 & .153 \\
\hline \hline & $1(\mathrm{U})$ & $2(\mathrm{P})$ & $3(\mathrm{O})$ & & \\
relative size & 0.582 & 0.279 & 0.140 & & \\
\cline { 1 - 5 } opera/operetta $\dagger$ & 0.007 & 0.048 & 0.159 & & \\
classical & 0.014 & 0.102 & 0.306 & & \\
rock/pop/jazz & 0.172 & 0.421 & 0.573 & & \\
exhibition & 0.010 & 0.508 & 0.991 & & \\
video arts & 0.014 & 0.060 & 0.358 & & \\
street arts & 0.027 & 0.193 & 0.687 & & \\
carnival & 0.079 & 0.195 & 0.294 & & \\
museum & 0.123 & 0.748 & 0.958 & & \\
\hline \hline
\end{tabular}

Note: $\nmid$ In model 4 , six residual local dependence terms are added between the indicators for 'opera and classical', 'pop and video arts', 'pop and street arts', 'pop and carnival', 'street arts' and 'carnival', and between 'video arts' and 'carnival'.

The bottom panel of Table 3 reports the latent class solution under model 4. Members of the largest latent class (comprising $58 \%$ of the sample) are least likely of all to attend music or visual art events. Their cultural consumption is largely restricted to one non-highbrow item in each domain, namely, 'rock, pop and jazz' $(p=.17)$ for music and 'museum' $(p=.12)$ for visual 
arts. Given this, I call this latent class univores (U). In contrast, members of the smallest latent class ( $14 \%$ of the sample) are, in relative terms at least, avid consumers of music and visual arts of all kinds. Compared to others, members of this latent class are considerably more likely to consume each of the eight items, whether they are highbrow or not. So I call them omnivores $(\mathrm{O})$. Finally, there is a third latent class that is in-between the other two classes both in terms of its size $(28 \%)$ and the probability of cultural consumption. I refer to this latent class as paucivores (P) because 'pauci', meaning few, is an apt description of the modest amount and limited range of cultural consumption of those in the second latent class.

Overall, the results of the latent class analysis are very similar to those reported by Chan and Goldthorpe (2007b,c) and Bunting et al. (2008). This threefold typology of $\mathrm{U}, \mathrm{P}$ and $\mathrm{O}$ serves as the independent variable in the analyses below (see also Alderson et al., 2007).

\section{B Regression tables}

\section{B.1 Trust and risk-taking}

1. Generally speaking would you say that most people can be trusted, or that you can't be too careful in dealing with people?

2. Are you generally a person who is fully prepared to take risks or do you try to avoid taking risks? 
Table 4: Determinants of trust and risk-taking

\begin{tabular}{|c|c|c|c|c|}
\hline & \multicolumn{2}{|c|}{ trust people } & \multicolumn{2}{|c|}{ risk-taking } \\
\hline age & $0.031 * * *$ & 0.002 & $-0.012 * * *$ & 0.001 \\
\hline female & $-0.159 * * *$ & 0.034 & $-0.299 * * *$ & 0.015 \\
\hline mixed & -0.310 & 0.165 & 0.056 & 0.068 \\
\hline asian & $-0.528 * * *$ & 0.079 & $-0.138 * * *$ & 0.033 \\
\hline black & $-0.849 * * *$ & 0.108 & 0.082 & 0.042 \\
\hline others & $-0.295 * *$ & 0.106 & 0.062 & 0.047 \\
\hline sep/div/wid & $-0.239 * * *$ & 0.047 & $0.146 * * *$ & 0.021 \\
\hline single & $-0.095 *$ & 0.044 & $0.086 * * *$ & 0.019 \\
\hline class III & $-0.111 *$ & 0.054 & $-0.169 * * *$ & 0.023 \\
\hline class IV & 0.127 & 0.067 & $0.133 * * *$ & 0.031 \\
\hline class $\mathrm{V}+\mathrm{VI}$ & -0.122 & 0.073 & -0.057 & 0.033 \\
\hline class VII & $-0.192 * * *$ & 0.058 & $-0.194 * * *$ & 0.025 \\
\hline status & $0.204 * *$ & 0.073 & -0.040 & 0.032 \\
\hline income & $0.190 * * *$ & 0.024 & $0.071 * * *$ & 0.010 \\
\hline cse & $0.149 *$ & 0.068 & $0.081 * *$ & 0.030 \\
\hline gcse & $0.200 * * *$ & 0.054 & $0.122 * * *$ & 0.024 \\
\hline a-level & $0.389 * * *$ & 0.070 & $0.157 * * *$ & 0.031 \\
\hline diploma & $0.399 * * *$ & 0.066 & $0.178 * * *$ & 0.030 \\
\hline degree & $0.665 * * *$ & 0.063 & $0.140 * * *$ & 0.028 \\
\hline paucivore & $0.234 * * *$ & 0.039 & $0.118 * * *$ & 0.017 \\
\hline omnivore & $0.430 * * *$ & 0.050 & $0.247 * * *$ & 0.022 \\
\hline constant & $-3.701 * * *$ & 0.235 & -0.021 & 0.098 \\
\hline$N$ & \multicolumn{2}{|c|}{21,383} & \multicolumn{2}{|c|}{21,289} \\
\hline$R^{2}$ & \multicolumn{2}{|c|}{0.067} & \multicolumn{2}{|c|}{0.092} \\
\hline $\begin{array}{l}\text { source } \\
\text { est.method }\end{array}$ & \multicolumn{2}{|c|}{$\begin{array}{c}\text { USoc wave } 1 \\
\text { logit }\end{array}$} & \multicolumn{2}{|c|}{$\begin{array}{c}\text { USoc wave } 1 \\
\text { logit }\end{array}$} \\
\hline
\end{tabular}

\section{B.2 The European Union}

1. Generally speaking, do you think that Britain's/the UK's membership of the European Union is a good thing, a bad thing or is it neither good nor bad?

2. Taking everything into consideration, would you say that Britain/the UK has on balance benefited or not from being a member of the European Union? 
Table 5: Determinants of attitudes about the EU

\begin{tabular}{|c|c|c|c|c|}
\hline \multirow[b]{2}{*}{ age } & \multicolumn{2}{|c|}{$\begin{array}{l}\text { EU membership } \\
\text { a good thing }\end{array}$} & \multicolumn{2}{|c|}{$\begin{array}{l}\text { UK benefit } \\
\text { from the EU }\end{array}$} \\
\hline & 0.005 & 0.004 & -0.003 & 0.004 \\
\hline female & $-0.343 * * *$ & 0.089 & $-0.365 * * *$ & 0.093 \\
\hline others & 0.335 & 0.232 & -0.015 & 0.245 \\
\hline sep/div/wid & -0.204 & 0.156 & 0.081 & 0.157 \\
\hline single & $0.274 *$ & 0.131 & $0.343 *$ & 0.139 \\
\hline class III & -0.098 & 0.121 & 0.005 & 0.129 \\
\hline class IV & -0.038 & 0.211 & 0.372 & 0.210 \\
\hline class V+VI & 0.113 & 0.235 & 0.272 & 0.238 \\
\hline class VII & -0.189 & 0.193 & 0.204 & 0.197 \\
\hline status & $0.927 * * *$ & 0.211 & $1.122 * * *$ & 0.225 \\
\hline income & 0.079 & 0.047 & 0.053 & 0.045 \\
\hline cse & 0.049 & 0.271 & -0.077 & 0.257 \\
\hline gcse & 0.363 & 0.208 & 0.105 & 0.200 \\
\hline a-level & $0.447 *$ & 0.218 & 0.103 & 0.214 \\
\hline diploma & $0.566 * *$ & 0.191 & $0.366 *$ & 0.183 \\
\hline degree & $1.323 * * *$ & 0.211 & $1.170 * * *$ & 0.208 \\
\hline paucivore & $0.293 * *$ & 0.094 & $0.319 * *$ & 0.100 \\
\hline omnivore & $0.950 * * *$ & 0.124 & $0.932 * * *$ & 0.131 \\
\hline constant & $-2.335 * * *$ & 0.571 & $-1.305 *$ & 0.547 \\
\hline$N$ & \multicolumn{2}{|c|}{3,595} & \multicolumn{2}{|c|}{3,081} \\
\hline$R^{2}$ & \multicolumn{2}{|c|}{0.118} & \multicolumn{2}{|c|}{0.107} \\
\hline $\begin{array}{l}\text { source } \\
\text { est.method }\end{array}$ & \multicolumn{2}{|c|}{$\begin{array}{c}\text { BHPS wave } 16 \\
\text { logit }\end{array}$} & \multicolumn{2}{|c|}{$\begin{array}{c}\text { BHPS wave } 16 \\
\text { logit }\end{array}$} \\
\hline
\end{tabular}

\section{B.3 National and subnational identity}

Looking at this card, what do you consider your national identity to be? You may choose as many or as few as apply.

1. English

2. Welsh

3. Scottish

4. Northern Irish

5. British

6. Irish

7. Other 
Table 6: Determinants of national identity of residents of England

\begin{tabular}{|c|c|c|c|c|c|c|}
\hline & \multicolumn{2}{|c|}{$\begin{array}{l}\text { British } \\
\text { v English }\end{array}$} & \multicolumn{2}{|c|}{$\begin{array}{c}\text { British and English } \\
\text { v English }\end{array}$} & \multicolumn{2}{|c|}{$\begin{array}{l}\text { Others } \\
\text { v English }\end{array}$} \\
\hline age & 0.001 & 0.002 & 0.000 & 0.002 & $-0.012 * * *$ & 0.003 \\
\hline female & $0.297 * * *$ & 0.043 & $0.232 * * *$ & 0.045 & $0.210 * * *$ & 0.059 \\
\hline mixed & $1.073 * * *$ & 0.171 & $-0.536 *$ & 0.253 & $1.579 * * *$ & 0.187 \\
\hline asian & $2.720 * * *$ & 0.138 & 0.081 & 0.199 & $2.939 * * *$ & 0.146 \\
\hline black & $2.241 * * *$ & 0.133 & -0.158 & 0.219 & $3.060 * * *$ & 0.138 \\
\hline others & $2.009 * * *$ & 0.198 & -0.110 & 0.296 & $3.542 * * *$ & 0.194 \\
\hline sep/div/wid & 0.057 & 0.057 & 0.069 & 0.060 & 0.119 & 0.081 \\
\hline single & 0.015 & 0.054 & -0.008 & 0.056 & -0.069 & 0.076 \\
\hline class III & -0.019 & 0.067 & 0.056 & 0.071 & -0.149 & 0.096 \\
\hline class IV & 0.083 & 0.085 & 0.060 & 0.089 & 0.164 & 0.117 \\
\hline class V+VI & -0.079 & 0.094 & 0.154 & 0.094 & -0.011 & 0.125 \\
\hline class VII & 0.020 & 0.072 & 0.057 & 0.074 & 0.168 & 0.097 \\
\hline status & $0.397 * * *$ & 0.091 & $0.266 * *$ & 0.094 & -0.005 & 0.119 \\
\hline income & 0.022 & 0.028 & 0.025 & 0.030 & 0.065 & 0.036 \\
\hline cse & $0.202 *$ & 0.083 & $0.285 * * *$ & 0.086 & $0.381 * * *$ & 0.113 \\
\hline gcse & 0.090 & 0.065 & $0.164 *$ & 0.066 & $-0.501 * * *$ & 0.098 \\
\hline a-level & $0.275 * *$ & 0.086 & $0.365 * * *$ & 0.090 & $0.374 * *$ & 0.118 \\
\hline diploma & $0.234 * *$ & 0.081 & $0.385 * * *$ & 0.084 & $0.473 * * *$ & 0.115 \\
\hline degree & $0.642 * * *$ & 0.077 & $0.549 * * *$ & 0.081 & $1.002 * * *$ & 0.104 \\
\hline paucivore & $0.205 * * *$ & 0.049 & $0.181 * * *$ & 0.052 & $0.365 * * *$ & 0.067 \\
\hline omnivore & $0.343 * * *$ & 0.064 & $0.253 * * *$ & 0.069 & $0.602 * * *$ & 0.083 \\
\hline constant & $-1.327 * * *$ & 0.271 & $-1.383 * * *$ & 0.290 & $-2.140 * * *$ & 0.352 \\
\hline$N$ & \multicolumn{6}{|c|}{20,353} \\
\hline$R^{2}$ & \multicolumn{6}{|c|}{0.065} \\
\hline $\begin{array}{l}\text { source } \\
\text { est.method }\end{array}$ & \multicolumn{6}{|c|}{$\begin{array}{c}\text { USoc wave } 1 \\
\text { multinomial logit }\end{array}$} \\
\hline
\end{tabular}

Note: ${ }^{*} p<0.05 ;{ }^{* *} p<0.01 ; * * * p<0.001$

\section{B.4 Sense of self}

We'd like to know how important various things are to your sense of who you are. Please think about each of the following and tick the box that indicates whether you think it is very important, fairly important, not very important or not at all important to your sense of who you are. Please tick one answer on each line.

1. Your profession?

2. Your level of education?

3. Your ethnic or racial background?

4. Your political beliefs? 
5. Your family?

6. Your gender?

7. Your age and life stage?

Table 7: Determinants of aspects of sense of self

\begin{tabular}{|c|c|c|c|c|c|c|c|c|}
\hline & \multicolumn{2}{|c|}{ Profession } & \multicolumn{2}{|c|}{ Education } & \multicolumn{2}{|c|}{ Race } & \multicolumn{2}{|c|}{ Politics } \\
\hline age & $-0.005 *$ & 0.002 & 0.002 & 0.002 & $0.007 * * *$ & 0.002 & $0.013 * * *$ & 0.002 \\
\hline female & $0.140 * *$ & 0.045 & $0.327 * * *$ & 0.041 & $0.194 * * *$ & 0.039 & $-0.310 * * *$ & 0.042 \\
\hline mixed & -0.236 & 0.180 & $0.382 *$ & 0.171 & $1.265 * * *$ & 0.155 & $0.604 * * *$ & 0.160 \\
\hline asian & $0.742 * * *$ & 0.108 & $0.935 * * *$ & 0.103 & $1.590 * * *$ & 0.091 & $0.677 * * *$ & 0.082 \\
\hline black & $0.390 * *$ & 0.124 & $1.039 * * *$ & 0.132 & $2.256 * * *$ & 0.137 & $1.035 * * *$ & 0.097 \\
\hline others & $0.355 *$ & 0.140 & $0.854 * * *$ & 0.149 & $1.326 * * *$ & 0.113 & $0.569 * * *$ & 0.111 \\
\hline sep/div/wid & 0.037 & 0.063 & -0.074 & 0.057 & -0.034 & 0.055 & -0.061 & 0.061 \\
\hline single & 0.032 & 0.055 & 0.023 & 0.052 & -0.021 & 0.048 & $0.160 * *$ & 0.051 \\
\hline class III & $-0.673 * * *$ & 0.066 & -0.060 & 0.061 & 0.003 & 0.059 & -0.025 & 0.066 \\
\hline class IV & 0.116 & 0.093 & -0.059 & 0.082 & 0.033 & 0.076 & 0.104 & 0.082 \\
\hline class $\mathrm{V}+\mathrm{VI}$ & -0.158 & 0.100 & $0.202 *$ & 0.091 & $0.180 *$ & 0.086 & $0.194 *$ & 0.096 \\
\hline class VII & $-0.546 * * *$ & 0.074 & 0.109 & 0.069 & $0.151 *$ & 0.065 & 0.109 & 0.071 \\
\hline status & $0.448 * * *$ & 0.095 & 0.121 & 0.088 & -0.106 & 0.082 & 0.038 & 0.089 \\
\hline income & $0.181 * * *$ & 0.036 & 0.059 & 0.033 & $0.065 *$ & 0.031 & -0.005 & 0.033 \\
\hline cse & $-0.252 * *$ & 0.082 & 0.085 & 0.075 & -0.148 & 0.079 & $-0.309 * * *$ & 0.089 \\
\hline gcse & $-0.261 * * *$ & 0.069 & 0.096 & 0.062 & $-0.256 * * *$ & 0.064 & $-0.331 * * *$ & 0.071 \\
\hline a-level & $-0.319 * * *$ & 0.085 & $0.601 * * *$ & 0.078 & $-0.239 * *$ & 0.079 & $-0.178 *$ & 0.085 \\
\hline diploma & 0.095 & 0.090 & $0.806 * * *$ & 0.078 & $-0.228 * *$ & 0.077 & $-0.162 *$ & 0.082 \\
\hline degree & 0.116 & 0.084 & $1.641 * * *$ & 0.078 & $-0.168 *$ & 0.072 & $0.151 *$ & 0.076 \\
\hline paucivore & -0.059 & 0.050 & -0.017 & 0.046 & $-0.140 * *$ & 0.043 & $0.219 * * *$ & 0.047 \\
\hline omnivore & -0.028 & 0.068 & 0.038 & 0.062 & $-0.237 * * *$ & 0.056 & $0.560 * * *$ & 0.057 \\
\hline constant & 0.223 & 0.331 & $-0.759 *$ & 0.304 & $-1.135 * * *$ & 0.288 & $-1.496 * * *$ & 0.306 \\
\hline$N$ & \multicolumn{2}{|c|}{17,098} & \multicolumn{2}{|c|}{17,079} & \multicolumn{2}{|c|}{16,524} & \multicolumn{2}{|c|}{16,210} \\
\hline$R^{2}$ & \multicolumn{2}{|c|}{0.044} & \multicolumn{2}{|c|}{0.086} & \multicolumn{2}{|c|}{0.041} & \multicolumn{2}{|c|}{0.031} \\
\hline $\begin{array}{l}\text { source } \\
\text { est.method }\end{array}$ & \multicolumn{2}{|c|}{$\begin{array}{c}\text { USoc wave } 2 \\
\text { logit }\end{array}$} & \multicolumn{2}{|c|}{$\begin{array}{c}\text { USoc wave } 2 \\
\text { logit }\end{array}$} & \multicolumn{2}{|c|}{$\begin{array}{c}\text { USoc wave } 2 \\
\text { logit }\end{array}$} & \multicolumn{2}{|c|}{$\begin{array}{c}\text { USoc wave } 2 \\
\text { logit }\end{array}$} \\
\hline
\end{tabular}


Table 8: Determinants of aspects of sense of self (cont'd)

\begin{tabular}{|c|c|c|c|c|c|c|}
\hline & \multicolumn{2}{|c|}{ Family } & \multicolumn{2}{|l|}{ Sex } & \multicolumn{2}{|c|}{ Age } \\
\hline age & $-0.011 *$ & 0.005 & $-0.007 * * *$ & 0.002 & $-0.005 * *$ & 0.002 \\
\hline female & $0.820 * * *$ & 0.090 & $0.490 * * *$ & 0.039 & $0.441 * * *$ & 0.041 \\
\hline mixed & 0.133 & 0.361 & $0.473 * *$ & 0.158 & -0.231 & 0.169 \\
\hline asian & $0.580 * *$ & 0.223 & $0.943 * * *$ & 0.097 & $0.857 * * *$ & 0.107 \\
\hline black & 0.441 & 0.266 & $1.303 * * *$ & 0.141 & $0.745 * * *$ & 0.131 \\
\hline others & 0.185 & 0.237 & $0.685 * * *$ & 0.120 & $0.610 * * *$ & 0.128 \\
\hline sep/div/wid & $-0.515 * * *$ & 0.127 & -0.030 & 0.056 & 0.058 & 0.059 \\
\hline single & $-0.882 * * *$ & 0.110 & -0.007 & 0.049 & $0.157 * *$ & 0.053 \\
\hline class III & $-0.269 *$ & 0.134 & -0.079 & 0.059 & $0.156 *$ & 0.065 \\
\hline class IV & -0.207 & 0.159 & 0.062 & 0.078 & 0.004 & 0.083 \\
\hline class V+VI & 0.009 & 0.211 & 0.081 & 0.088 & $0.213 *$ & 0.093 \\
\hline class VII & 0.044 & 0.152 & 0.109 & 0.068 & 0.079 & 0.070 \\
\hline status & -0.158 & 0.181 & $-0.284 * * *$ & 0.083 & 0.087 & 0.087 \\
\hline income & $0.269 * * *$ & 0.070 & 0.040 & 0.032 & 0.059 & 0.033 \\
\hline cse & -0.117 & 0.189 & -0.134 & 0.081 & $-0.161 *$ & 0.082 \\
\hline gcse & -0.005 & 0.168 & $-0.392 * * *$ & 0.066 & $-0.201 * *$ & 0.066 \\
\hline a-level & -0.178 & 0.194 & $-0.373 * * *$ & 0.080 & -0.085 & 0.083 \\
\hline diploma & -0.180 & 0.187 & $-0.338 * * *$ & 0.079 & -0.088 & 0.083 \\
\hline degree & $-0.375 *$ & 0.180 & $-0.188 *$ & 0.075 & -0.036 & 0.077 \\
\hline paucivore & -0.187 & 0.096 & -0.073 & 0.043 & 0.062 & 0.046 \\
\hline omnivore & $-0.257 *$ & 0.126 & -0.055 & 0.056 & 0.077 & 0.060 \\
\hline constant & $1.673 * *$ & 0.615 & 0.550 & 0.290 & 0.414 & 0.303 \\
\hline$N$ & \multicolumn{2}{|c|}{17,352} & \multicolumn{2}{|c|}{16,889} & \multicolumn{2}{|c|}{17,162} \\
\hline$R^{2}$ & \multicolumn{2}{|c|}{0.046} & \multicolumn{2}{|c|}{0.025} & \multicolumn{2}{|c|}{0.018} \\
\hline $\begin{array}{l}\text { source } \\
\text { est.method }\end{array}$ & \multicolumn{2}{|c|}{$\begin{array}{c}\text { USoc wave } 2 \\
\text { logit }\end{array}$} & \multicolumn{2}{|c|}{$\begin{array}{c}\text { USoc wave } 2 \\
\text { logit }\end{array}$} & \multicolumn{2}{|c|}{$\begin{array}{c}\text { USoc wave } 2 \\
\text { logit }\end{array}$} \\
\hline
\end{tabular}




\section{B.5 Subjective social class membership}

1. Do you think of yourself as belonging to any particular social class?

2. (If you had to choose) Which social class would you say you belong to?

Table 9: Determinants of subjective social class membership

\begin{tabular}{lcl|cc}
\hline \hline & \multicolumn{2}{c|}{$\begin{array}{c}\text { social class } \\
\text { membership }\end{array}$} & \multicolumn{2}{c}{ middle } \\
class
\end{tabular}

\section{B.6 Politics}

1. Interest in politics: How interested would you say you are in politics?

2. Left-right political attitudes

(a) Ordinary people get their fair share of the nation's wealth.

(b) There is one law for the rich and one for the poor. 
(c) Private enterprise is the best way to solve the UK's economic problems.

(d) Major public services and industries ought to be in state ownership.

(e) It is the government's responsibility to provide a job for everyone who wants one.

(f) Strong trade unions are needed to protect the working conditions and wages of employees.

3. Maximum income: The government should place an upper limit on the amount of money that any one person can make.

4. Gender role

(a) A pre-school child is likely to suffer if his or her mother works.

(b) All in all, family life suffers when the woman has a full-time job.

(c) Both the husband and wife should contribute to the household income.

(d) A husband's job is to earn money; a wife's job is to look after the home and family.

(e) Employers should make special arrangements to help mothers combine jobs and childcare.

5. Homosexuality: Homosexual relationships are always wrong.

6. Climate change and lifestyle

(a) Which of these best describes how you feel about your current lifestyle and the environment?

(b) And which of these would you say best describes your current lifestyle?

(c) Do you agree or disagree that being green is an alternative lifestyle, it's not for the majority?

(d) I don't believe my behaviour and everyday lifestyle contribute to climate change. 
(e) I would be prepared to pay more of environmentally friendly products.

(f) If things continue on their current course, we will soon experience a major environmental disaster.

(g) The so-called 'environmental crisis' facing humanity has been greatly exaggerated.

(h) Climate change is beyond control - it's too late to do anything about it.

(i) The effect of climate change is too far in the future to really worry me.

(j) Any changes I made to help the environment need to fit in with my lifestyle.

(k) It's not worth me doing things to help the environment if others don't do the same.

(l) It's not worth Britain trying to combat climate change, because other countries will just cancel out what we do.

(m) People in the UK will be affected by climate change in the next 30 years.

(n) People in the UK will be affected by climate change in the next 200 years. 
Table 10: Determinants of interest in politics, left-right attitude and views on maximum income

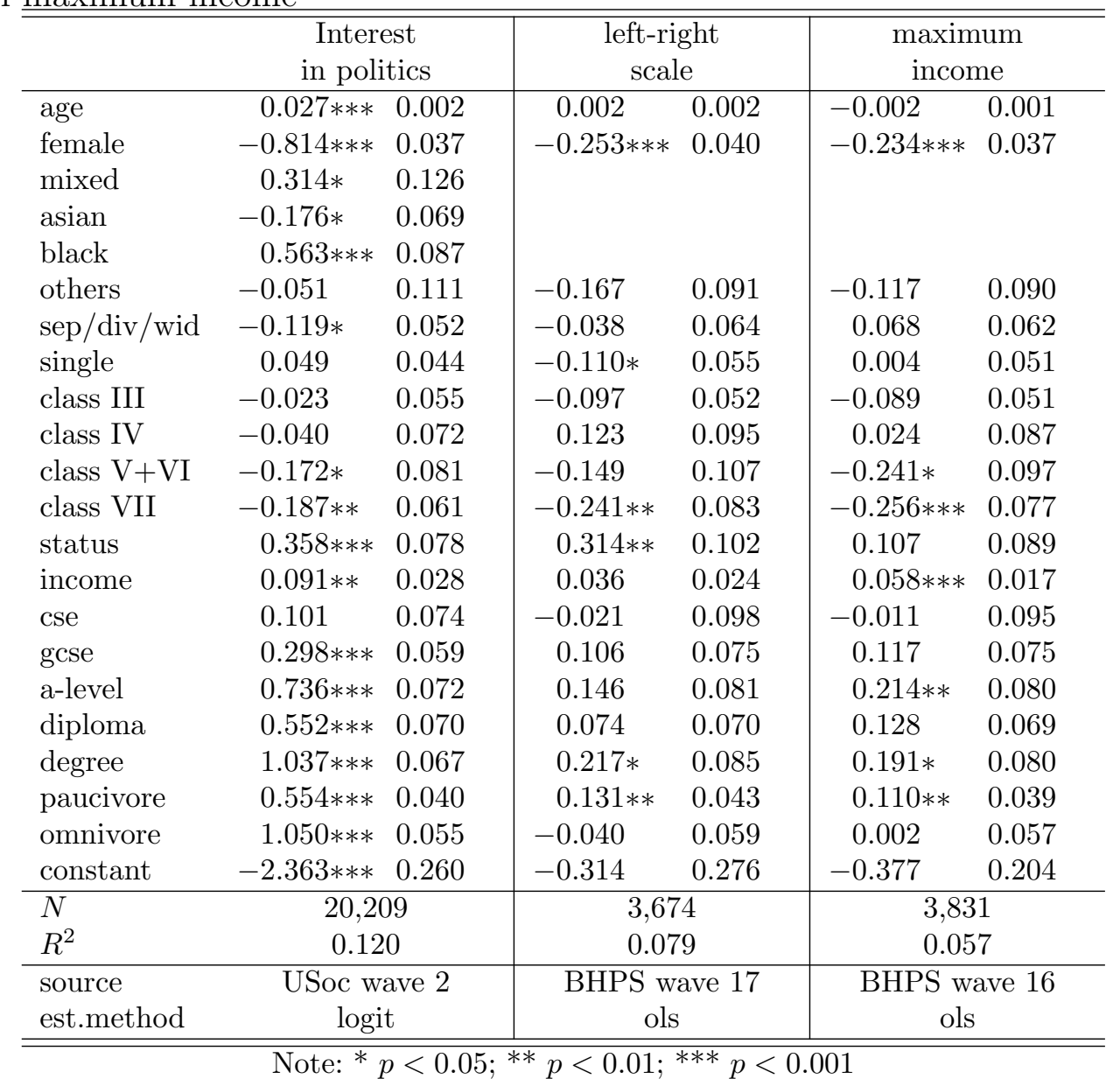


Table 11: Determinants of views on gender role, homosexuality and environment and lifestyle

\begin{tabular}{|c|c|c|c|c|c|c|}
\hline \multirow[b]{2}{*}{ age } & \multicolumn{2}{|c|}{$\begin{array}{l}\text { gender } \\
\text { role }\end{array}$} & \multicolumn{2}{|c|}{ homosexuality } & \multicolumn{2}{|c|}{$\begin{array}{c}\text { environment \& } \\
\text { lifestyle }\end{array}$} \\
\hline & $-0.016 * * *$ & 0.001 & $-0.016 * * *$ & 0.002 & $0.004 * * *$ & 0.001 \\
\hline female & $0.291 * * *$ & 0.017 & $0.377 * * *$ & 0.036 & $0.179 * * *$ & 0.016 \\
\hline mixed & 0.085 & 0.070 & & & $0.275 * * *$ & 0.066 \\
\hline asian & $-0.365 * * *$ & 0.034 & & & $-0.106 * * *$ & 0.032 \\
\hline black & $0.095 *$ & 0.045 & & & -0.031 & 0.041 \\
\hline others & $-0.197 * * *$ & 0.047 & $-0.531 * * *$ & 0.097 & -0.055 & 0.044 \\
\hline sep/div/wid & $0.102 * * *$ & 0.024 & 0.027 & 0.061 & -0.013 & 0.022 \\
\hline single & $0.090 * * *$ & 0.021 & 0.020 & 0.050 & 0.027 & 0.021 \\
\hline class III & $-0.053 *$ & 0.026 & -0.075 & 0.049 & $-0.052 *$ & 0.026 \\
\hline class IV & $-0.292 * * *$ & 0.034 & -0.050 & 0.083 & -0.021 & 0.034 \\
\hline class $\mathrm{V}+\mathrm{VI}$ & -0.033 & 0.038 & -0.127 & 0.089 & $-0.079 *$ & 0.035 \\
\hline class VII & $-0.131 * * *$ & 0.028 & $-0.181 *$ & 0.074 & $-0.079 * *$ & 0.027 \\
\hline status & -0.044 & 0.036 & 0.160 & 0.086 & $0.098 * *$ & 0.035 \\
\hline income & $0.054 * * *$ & 0.014 & 0.039 & 0.024 & $0.055 * * *$ & 0.011 \\
\hline cse & -0.018 & 0.034 & -0.050 & 0.096 & $0.095 * *$ & 0.032 \\
\hline gcse & 0.005 & 0.028 & 0.106 & 0.077 & $0.168 * * *$ & 0.025 \\
\hline a-level & -0.021 & 0.034 & $0.186 *$ & 0.079 & $0.292 * * *$ & 0.034 \\
\hline diploma & 0.007 & 0.033 & 0.090 & 0.069 & $0.317 * * *$ & 0.031 \\
\hline degree & $0.062 *$ & 0.031 & $0.299 * * *$ & 0.080 & $0.517 * * *$ & 0.030 \\
\hline paucivore & -0.002 & 0.019 & $0.181 * * *$ & 0.041 & $0.227 * * *$ & 0.019 \\
\hline omnivore & $0.127 * * *$ & 0.024 & $0.312 * * *$ & 0.055 & $0.438 * * *$ & 0.023 \\
\hline constant & 0.142 & 0.127 & -0.045 & 0.272 & $-1.061 * * *$ & 0.104 \\
\hline$N$ & \multicolumn{2}{|c|}{17,167} & \multicolumn{2}{|c|}{3,679} & \multicolumn{2}{|c|}{18,891} \\
\hline$R^{2}$ & \multicolumn{2}{|c|}{0.088} & \multicolumn{2}{|c|}{0.170} & \multicolumn{2}{|c|}{0.126} \\
\hline $\begin{array}{l}\text { source } \\
\text { est.method }\end{array}$ & \multicolumn{2}{|c|}{$\begin{array}{c}\text { USoc wave } 2 \\
\text { ols }\end{array}$} & \multicolumn{2}{|c|}{$\begin{array}{c}\text { BHPS wave } 18 \\
\text { ols }\end{array}$} & \multicolumn{2}{|c|}{$\begin{array}{c}\text { USoc wave } 1 \\
\text { ols }\end{array}$} \\
\hline
\end{tabular}




\section{B.7 Big Five Personality Traits}

The following questions are about how you see yourself as a person. Please tick the number which best describes how you see yourself where 1 means 'does not apply to me at all' and 7 means 'applies to me perfectly'. I see myself as someone who ...

(a) Is sometimes rude to others. [A]

(b) Does a thorough job. $[\mathrm{C}]$

(c) Is talkative. $[\mathrm{E}]$

(d) Worries a lot. $[\mathrm{N}]$

(e) Is original, comes up with new ideas. [O]

(f) Have a forgiving nature. [A]

(g) Tends to be lazy. [C]

(h) Is outgoing, sociable. [E]

(i) Gets nervous easily. [N]

(j) Values artistic, aesthetic experiences. [O]

(k) Is considerate and kind to almost everyone. [A]

(l) Does things efficiently. [C]

(m) Is reserved. [E]

(n) Is relaxed, handles stress well. [N]

(o) Has an active imagination. [O]

Note: Each of the big five personality traits are measured by three items, indicated in the listing above by $[\mathrm{A}],[\mathrm{C}],[\mathrm{E}],[\mathrm{N}]$, and $[\mathrm{O}]$, which stand for agreeableness, conscientiousness, extroversion, neuroticism and openness respectively. In addition, in forming the additive scales, the coding of items (a), (g), (m), and (n) are reversed. 
Table 12: Determinants of Big Five personality traits

\begin{tabular}{|c|c|c|c|c|c|c|}
\hline & \multicolumn{2}{|c|}{ agreeableness } & \multicolumn{2}{|c|}{ conscientiousness } & \multicolumn{2}{|c|}{ extraversion } \\
\hline age & -0.001 & 0.002 & 0.001 & 0.002 & $-0.012 * * *$ & 0.002 \\
\hline female & $0.347 * * *$ & 0.040 & $0.229 * * *$ & 0.039 & $0.245 * * *$ & 0.039 \\
\hline others & -0.103 & 0.106 & -0.168 & 0.113 & -0.076 & 0.089 \\
\hline sep/div/wid & -0.052 & 0.062 & -0.100 & 0.067 & 0.042 & 0.059 \\
\hline single & $-0.164 * *$ & 0.059 & $-0.211 * * *$ & 0.058 & -0.007 & 0.054 \\
\hline class III & 0.050 & 0.052 & $-0.121 *$ & 0.053 & -0.059 & 0.054 \\
\hline class IV & 0.020 & 0.089 & 0.045 & 0.087 & -0.011 & 0.092 \\
\hline class V+VI & -0.022 & 0.102 & -0.018 & 0.093 & -0.073 & 0.099 \\
\hline class VII & 0.034 & 0.083 & $-0.166 *$ & 0.081 & -0.144 & 0.083 \\
\hline status & 0.047 & 0.094 & -0.109 & 0.093 & -0.111 & 0.098 \\
\hline income & $-0.054 *$ & 0.025 & $0.077 * *$ & 0.027 & $0.054 *$ & 0.027 \\
\hline cse & -0.041 & 0.096 & -0.077 & 0.101 & 0.042 & 0.094 \\
\hline gcse & 0.100 & 0.079 & 0.153 & 0.080 & 0.116 & 0.076 \\
\hline a-level & 0.020 & 0.087 & 0.068 & 0.085 & -0.003 & 0.080 \\
\hline diploma & 0.081 & 0.076 & $0.173 *$ & 0.075 & 0.123 & 0.070 \\
\hline degree & -0.033 & 0.087 & 0.017 & 0.086 & -0.091 & 0.084 \\
\hline paucivore & 0.029 & 0.042 & -0.031 & 0.041 & $0.144 * * *$ & 0.043 \\
\hline omnivore & -0.075 & 0.055 & $-0.166 * *$ & 0.055 & $0.288 * * *$ & 0.057 \\
\hline constant & 0.392 & 0.280 & $-0.906 * *$ & 0.298 & -0.223 & 0.309 \\
\hline$N$ & \multicolumn{2}{|c|}{3,707} & \multicolumn{2}{|c|}{3,701} & \multicolumn{2}{|c|}{3,706} \\
\hline$R^{2}$ & \multicolumn{2}{|c|}{0.044} & \multicolumn{2}{|c|}{0.039} & \multicolumn{2}{|c|}{0.053} \\
\hline $\begin{array}{l}\text { source } \\
\text { est.method }\end{array}$ & \multicolumn{2}{|c|}{$\begin{array}{c}\text { BHPS wave } 15 \\
\text { ols }\end{array}$} & \multicolumn{2}{|c|}{$\begin{array}{c}\text { BHPS wave } 15 \\
\text { ols }\end{array}$} & \multicolumn{2}{|c|}{$\begin{array}{c}\text { BHPS wave } 15 \\
\text { ols }\end{array}$} \\
\hline
\end{tabular}

Note: ${ }^{*} p<0.05 ;{ }^{* *} p<0.01 ;{ }^{* * *} p<0.001$ 
Table 13: Determinants of Big Five personality traits (cont'd)

\begin{tabular}{|c|c|c|c|c|}
\hline & \multicolumn{2}{|c|}{ Neuroticism } & \multicolumn{2}{|c|}{ Openness } \\
\hline age & $-0.004 * *$ & 0.002 & $-0.007 * * *$ & 0.002 \\
\hline female & $0.483 * * *$ & 0.037 & $-0.104 * *$ & 0.037 \\
\hline others & -0.073 & 0.094 & -0.073 & 0.097 \\
\hline $\operatorname{sep} / \operatorname{div} /$ wid & 0.102 & 0.061 & -0.005 & 0.064 \\
\hline single & 0.013 & 0.055 & 0.069 & 0.052 \\
\hline class III & $0.165 * *$ & 0.051 & -0.052 & 0.049 \\
\hline class IV & 0.055 & 0.082 & 0.038 & 0.084 \\
\hline class V+VI & 0.165 & 0.096 & -0.011 & 0.087 \\
\hline class VII & $0.235 * *$ & 0.077 & $-0.191 *$ & 0.076 \\
\hline status & $0.200 *$ & 0.090 & 0.042 & 0.088 \\
\hline income & $-0.103 * * *$ & 0.027 & 0.017 & 0.026 \\
\hline cse & -0.061 & 0.090 & -0.023 & 0.094 \\
\hline gcse & -0.132 & 0.072 & $0.188 *$ & 0.080 \\
\hline a-level & -0.075 & 0.081 & $0.286 * * *$ & 0.084 \\
\hline diploma & $-0.178 * *$ & 0.068 & $0.315 * * *$ & 0.075 \\
\hline degree & 0.041 & 0.079 & $0.425 * * *$ & 0.087 \\
\hline paucivore & -0.038 & 0.041 & $0.271 * * *$ & 0.040 \\
\hline omnivore & -0.010 & 0.051 & $0.583 * * *$ & 0.049 \\
\hline constant & $0.956 * *$ & 0.299 & -0.140 & 0.302 \\
\hline$N$ & \multicolumn{2}{|c|}{3,709} & \multicolumn{2}{|c|}{3,697} \\
\hline$R^{2}$ & \multicolumn{2}{|c|}{0.098} & \multicolumn{2}{|c|}{0.133} \\
\hline $\begin{array}{l}\text { source } \\
\text { est.method }\end{array}$ & \multicolumn{2}{|c|}{$\begin{array}{c}\text { BHPS wave } 15 \\
\text { ols }\end{array}$} & \multicolumn{2}{|c|}{$\begin{array}{c}\text { BHPS wave } 15 \\
\text { ols }\end{array}$} \\
\hline
\end{tabular}

